(W)

Check for

Cite as

Nano-Micro Lett.

(2021) 13:151

Received: 12 April 2021

Accepted: 7 June 2021

Published online: 30 June 2021

(C) The Author(s) 2021

\section{Porous Carbon Architecture Assembled by Cross-Linked Carbon Leaves with Implanted Atomic Cobalt for High-Performance Li-S Batteries}

\author{
Ruirui Wang ${ }^{1}$, Renbing Wu ${ }^{1}{ }^{凶}$, Chaofan Ding ${ }^{1}$, Ziliang Chen ${ }^{1}$, Hongbin Xu ${ }^{1}$, \\ Yongfeng $\mathrm{Liu}^{2}{ }^{凶}$, Jichao Zhang ${ }^{3}$, Yuan $\mathrm{Ha}^{1}$, Ben Fei ${ }^{1}$, Hongge Pan ${ }^{2,4} \bowtie$
}

\title{
HIGHLIGHTS
}

- $\mathrm{SiO}_{2}$-mediated ZIF-L is developed to prepare $\mathrm{Co}-\mathrm{N}_{4} @ 2 \mathrm{D} / 3 \mathrm{D}$ carbon.

- $\mathrm{Co}-\mathrm{N}_{4} @ 2 \mathrm{D} / 3 \mathrm{D}$ integrates the advantages of 0D Co single atom and 2D/3D carbon support.

- $\mathrm{Co}-\mathrm{N}_{4} @ 2 \mathrm{D} / 3 \mathrm{D}$ carbon-based sulfur cathode enables a high reversible specific capacity and low capacity fading rate.

\begin{abstract}
The practical application of lithium-sulfur batteries is severely hampered by the poor conductivity, polysulfide shuttle effect and sluggish reaction kinetics of sulfur cathodes. Herein, a hierarchically porous three-dimension (3D) carbon architecture assembled by cross-linked carbon leaves with implanted atomic $\mathrm{Co}-\mathrm{N}_{4}$ has been delicately developed as an advanced sulfur host through a $\mathrm{SiO}_{2}$-mediated zeolitic imidazolate framework-L (ZIF-L) strategy. The unique 3D architectures not only provide a highly conductive network for fast electron transfer and buffer the volume change upon lithiation-delithiation process but also endow rich interface with full exposure of $\mathrm{Co}-\mathrm{N}_{4}$ active sites to boost the lithium polysulfides adsorption and conversion. Owing to the accelerated kinetics and suppressed shuttle effect, the as-prepared sulfur cathode exhibits a superior electrochemical perfor-

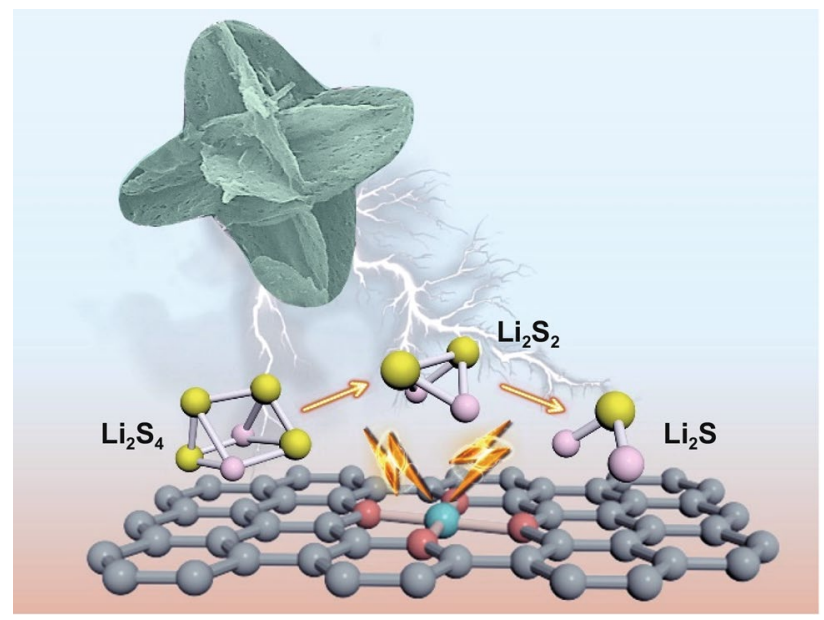
mance with a high reversible specific capacity of $695 \mathrm{mAh} \mathrm{g}^{-1}$ at $5 \mathrm{C}$ and a low capacity fading rate of $0.053 \%$ per cycle over 500 cycles at $1 \mathrm{C}$. This work may provide a promising solution for the design of an advanced sulfur-based cathode toward high-performance $\mathrm{Li}-\mathrm{S}$ batteries.
\end{abstract}

KEYWORDS Single-atom Co; 3D porous carbon architecture; Cathode; Lithium-sulfur battery

\footnotetext{
Renbing Wu, rbwu@fudan.edu.cn; Yongfeng Liu, mselyf@zju.edu.cn; Hongge Pan, honggepan@zju.edu.cn

Department of Materials Science, Fudan University, Shanghai 200433, People's Republic of China

2 State Key Laboratory of Silicon Materials and School of Materials Science and Engineering, Zhejiang University, Hangzhou 310027, People's Republic of China

3 Shanghai Synchrotron Radiation Facility, Zhangjiang Laboratory, Shanghai Advanced Research Institute, Chinese Academy of Sciences, Shanghai 201204, People's Republic of China

4 Institute of Science and Technology for New Energy, Xi'an Technological University, Xi'an 710021, People's Republic of China
} 


\section{Introduction}

Nickel-metal hydride battery and lithium-ion battery have been widely used in portable electronic devices and energy storage systems [1-7]. Nevertheless, they are difficult to meet the ever-increasing demands on high energy density for future electric vehicles. Lithium-sulfur ( $\mathrm{Li}-\mathrm{S}$ ) battery has been considered as one of the most promising nextgeneration energy storage systems due to the high energy density as well as resource abundance and environment benignity of the sulfur cathode [8-10]. However, the practical implementation of $\mathrm{Li}-\mathrm{S}$ is seriously hindered by the sulfur cathode associated with poor electronic conductivity of sulfur, huge volume variation during operation, shuttle effect of intermediate lithium polysulfides (LiPSs) and sluggish LiPSs conversion kinetics, leading to inferior cycling stability and unsatisfactory coulombic efficiency [11-15].

Various strategies including designing advanced sulfur hosts, constructing functional separators and optimizing electrolyte additives have been proposed to address the above-mentioned problems [16-18]. Among them, encapsulating $\mathrm{S}$ particles into porous carbon matrix is deemed to be one of the most popular ways for enhancing the electrical conductivity of the cathode and alleviating the volume oscillation $[19,20]$. Unfortunately, the carbon matrix is usually nonpolar, which shows unfavorable affinity to polar LiPSs and thus only functions as physical barrier to achieve a very limited LiPSs shutting inhibition. In this regard, polar species (e.g., non-metal heteroatom dopants, transition metalbased compounds and coordination polymers) with favorable affinity to LiPSs have been incorporated into carbon matrix to chemically interact with LiPSs and restrain its diffusion in the electrochemical process [21-24]. Nevertheless, these materials may suffer from various problems when used as sulfur host. Specifically, the non-metal heteroatom dopants have a limited effect for the LiPSs adsorption and conversion due to the small amount [25]. The transition metalbased compounds on carbon matrix are easily aggregated, while the coordination polymers have a weak conductivity and thus may block the electron/ion transfer and lower the kinetics of LiPSs conversion [26, 27].

Recently, atomically dispersed transition metal atoms anchored on nitrogen-doped carbon matrix (TM-N-C) have been demonstrated as a single-atom catalyst for $\mathrm{Li}-\mathrm{S}$ batteries $[28,29]$. Due to the maximum atom utilization and unique electronic structure, $\mathrm{TM}-\mathrm{N}-\mathrm{C}$ can not only mitigate LiPSs shutting through a strong chemical interaction but also efficiently facilitates the LiPSs conversion process via a catalytic effect [30, 31]. For example, Du et al. reported a synthesis of single-atom Co embedded in nitrogen-doped graphene $(\mathrm{Co}-\mathrm{N}-\mathrm{C})$ and demonstrated that the $\mathrm{Co}-\mathrm{N}-\mathrm{C}$ was favorable for both the formation and decomposition of $\mathrm{Li}_{2} \mathrm{~S}$ in lithiation and delithiation process [32]. Xie et al. implanted atomic Co dopants within mesoporous carbon and verified that they could serve as active sites to improve the interaction with LiPSs and accelerate the kinetics reactions of the sulfur redox [33]. Zhang et al. employed porous Mo-N-C nanosheets with atomically dispersed $\mathrm{Mo}-\mathrm{N}_{2} / \mathrm{C}$ sites as a sulfur host to prepare cathode [34]. It was found that the Mo- $\mathrm{N}_{2} / \mathrm{C}$ could greatly decrease the energy barriers for the deposition and decomposition of $\mathrm{Li}_{2} \mathrm{~S}$, leading to improved LiPSs conversion kinetics and excellent electrochemical performance in Li-S battery. Despite these pioneer progress that has been made, the application of single-atom catalyst in $\mathrm{Li}-\mathrm{S}$ batteries remain in its infancy. Moreover, most reported carbon matrix to support single-atom metal is usually limited to two-dimensional (2D) carbon nanosheets/ graphene or three-dimension (3D) carbon spheres/polyhedra, and thus the exposure and utilization of active sites is still unsatisfactory.

Herein, for the first time, a 3D carbon architecture assembled by cross-linked 2D porous carbon leaves with atomically dispersed $\mathrm{Co}-\mathrm{N}_{4}\left(\mathrm{Co}-\mathrm{N}_{4} @ 2 \mathrm{D} / 3 \mathrm{D}\right.$ carbon) through a $\mathrm{SiO}_{2}$-mediated zeolitic imidazolate framework-L (ZIF-L) strategy is developed and employed as a multifunctional sulfur host toward Li-S batteries. Within this Co- $\mathrm{N}_{4} @ 2 \mathrm{D} / 3 \mathrm{D}$ carbon host, the 3D architecture can effectively prevent the stacking of 2D carbon subunits and ensure high structure stability, enabling a full exposure of active interfaces with richly accessible $\mathrm{Co}-\mathrm{N}_{4}$ catalytic active sites and strong interaction with LiPSs. Meanwhile, the porous 2D carbon leaves not only allow abundant space for the volume variation of sulfur but also provide a rapid electron/ion transfer pathway in collaboration with a cross-linked assembly way, further contributing to facile sulfur redox kinetics and stable sulfur electrochemistry. As a result, the sulfur-loaded Co- $\mathrm{N}_{4} @ 2 \mathrm{D} / 3 \mathrm{D}$ carbon cathodes could achieve a superior rate capability $\left(695 \mathrm{mAh} \mathrm{g}^{-1}\right.$ at $\left.5 \mathrm{C}\right)$ and long-term cycling stability $(0.053 \%$ decay rate per cycle after 500 cycles at $1 \mathrm{C})$. 


\section{Experiment Section}

\subsection{Synthesis of Co/Zn-ZIF-L}

First, $40 \mathrm{mg}$ of $\mathrm{Co}(\mathrm{acac})_{2} \cdot 6 \mathrm{H}_{2} \mathrm{O}, 820 \mathrm{mg}$ of $\mathrm{Zn}\left(\mathrm{NO}_{3}\right)_{2} \cdot 6 \mathrm{H}_{2} \mathrm{O}$ and $1.64 \mathrm{~g}$ of 2-methylimidazole were dissolved into $80 \mathrm{~mL}$ of DI water, followed by stirring for $30 \mathrm{~min}$. Afterward, the solution was placed at room temperature for $4 \mathrm{~h}$. The resultant Co/Zn-ZIF-L precursor was obtained by centrifugation, washed with DI water and dried in a vacuum at $60{ }^{\circ} \mathrm{C}$.

\subsection{Synthesis of Co/Zn-ZIF-L@ $@ \mathrm{SiO}_{2}$}

In a typical synthesis, $600 \mathrm{mg}$ of Co/Zn-ZIF-L powder was added into $240 \mathrm{~mL}$ of DI water in the presence of cetyltrimethylammonium bromide (CTAB) $(150 \mathrm{mg})$ and $\mathrm{NaOH}$ $(57.6 \mathrm{mg}$ ). Afterward, $6 \mathrm{~mL}$ of methanol dissolved with $1.5 \mathrm{~mL}$ of tetraethyl orthosilicate was drop-wise added into the above solution and then stirred for $30 \mathrm{~min}$. The $\mathrm{Co} / \mathrm{Zn}$ ZIF-L@ $\mathrm{SiO}_{2}$ was obtained after collecting the precipitate and dried at $60{ }^{\circ} \mathrm{C}$ for $12 \mathrm{~h}$.

\subsection{Preparation of $\mathrm{Co}-\mathrm{N}_{4} @ 2 \mathrm{D} / 3 \mathrm{D}$ Carbon}

A clean porcelain boat loaded with Co/Zn-ZIF-L- @ $\mathrm{SiO}_{2}$ was heated to $930{ }^{\circ} \mathrm{C}$ with a ramp rate of $2{ }^{\circ} \mathrm{C} \mathrm{min}^{-1}$ and maintained at this temperature for $3 \mathrm{~h}$ under the flowing nitrogen to obtain Co- $\mathrm{N}_{4} @ 2 \mathrm{D} / 3 \mathrm{D}$ carbon@ $\mathrm{SiO}_{2}$. Finally, the $\mathrm{SiO}_{2}$ coating was etched by $1 \mathrm{M}$ HF to generate $\mathrm{Co}-\mathrm{N}_{4} @ 2 \mathrm{D} / 3 \mathrm{D}$ carbon composites. The preparation of nitrogen-doped carbon with implanted cobalt single atoms $\left(\mathrm{Co}-\mathrm{N}_{4} @\right.$ carbon) was similar to that for making $\mathrm{Co}-\mathrm{N}_{4} @ 2 \mathrm{D} / 3 \mathrm{D}$ carbon except no $\mathrm{SiO}_{2}$ coating. The preparation of $2 \mathrm{D}$ nitrogen-doped carbon leaves (2D carbon) was similar to that for making $\mathrm{Co}-\mathrm{N}_{4} @ 2 \mathrm{D} / 3 \mathrm{D}$ carbon except no adding $\mathrm{Co}(\mathrm{acac})_{2} \cdot 6 \mathrm{H}_{2} \mathrm{O}$.

\subsection{Preparation of $\mathrm{S} @ \mathrm{Co}-\mathrm{N}_{4} @ 2 \mathrm{D} / 3 \mathrm{D}$ Carbon Composites}

The preparation of $\mathrm{S} @ \mathrm{Co}-\mathrm{N}_{4} @ 2 \mathrm{D} / 3 \mathrm{D}$ carbon composites was achieved by a melt-diffusion method. In a typical process, the sulfur powder and the $\mathrm{Co}-\mathrm{N}_{4} @ 2 \mathrm{D} / 3 \mathrm{D}$ carbon were ground together in a mass ratio of $3: 1$ and treated at $155^{\circ} \mathrm{C}$ for $12 \mathrm{~h}$ in a sealed autoclave. After that, the obtained mixture was placed in a tube furnace and heated to $230{ }^{\circ} \mathrm{C}$ for 30 min under the flowing nitrogen to obtain the resulting S@ $\mathrm{Co}-\mathrm{N}_{4} @ 2 \mathrm{D} / 3 \mathrm{D}$ carbon composites.

\subsection{Materials Characterizations}

The crystal structures of products were characterized by $\mathrm{X}$-ray diffractometer (XRD) in D8 ADVANCE with $\mathrm{Cu}$ $\mathrm{K} \alpha$ radiation. Field-emission scanning electron microscope (FESEM, ZEIS, Ultra-55) and transmission electron microscope (TEM, JEOL-2100) characterizations were performed to investigate the morphology and microstructure of samples. X-ray photoelectron spectroscopy (XPS) measurement was conducted to identify surface states of products on Thermo ESCALAB 250XI (Mg K $\alpha$ radiation source). The element contents of products were determined through Thermogravimetric analysis (METTLER TOLEDO TGA2). The porosity of samples was investigated through $\mathrm{N}_{2}$ sorption measurements on Autosorb IQ Gas Sorption instrument.

\subsection{Electrochemical Measurements}

The 2032-type coin half-cells were assembled in a glove-box $\left(\mathrm{H}_{2} \mathrm{O}\right.$ and $\left.\mathrm{O}_{2}<0.1 \mathrm{ppm}\right)$ filled with Ar. S@Co-N $\mathrm{N}_{4} @ 2 \mathrm{D} / 3 \mathrm{D}$ carbon, Celgard 2400 membrane and Li metal foil were used as active material, separator and counter electrode, respectively. $1 \mathrm{M}$ lithium bis-trifluoromethanesulfonimide (LiTFSI) in a mixture of DOL and DME (1:1 in volume) with $2.0 \mathrm{wt} \% \mathrm{LiNO}_{3}$ additive was used as the electrolyte. The Galvanostatic charge-discharge test was carried out over the voltage range of $1.7-2.8 \mathrm{~V}$ on a Land-CT2001A battery test system at room temperature. The cyclic voltammetry $(\mathrm{CV})$ curves were collected over the same potential at $0.1 \mathrm{mV} \mathrm{s}^{-1}$ on AutoLab-PGSTAT302N electrochemical work station. The electrochemical impedance spectroscopy (EIS) was also examined in a $0.1 \mathrm{MHz}-0.01 \mathrm{~Hz}$ frequency range on above workstation.

\subsection{Adsorption Test of Lithium Polysulfide}

$0.2 \mathrm{M} \mathrm{Li}_{2} \mathrm{~S}_{6}$ solution was prepared by dissolving a certain amount of $\mathrm{S}$ and $\mathrm{Li}_{2} \mathrm{~S}$ (1:5 by molar ratio) in 1,2-dioxolane (DOL)/dimethoxymethane (DME) (1:1 in volume). The adsorption tests were carried out by adding $10 \mathrm{mg}$ of 
Co- $\mathrm{N}_{4} @ 2 \mathrm{D} / 3 \mathrm{D}$ carbon, $\mathrm{Co}-\mathrm{N}_{4} @$ carbon and 2D carbon into $3 \mathrm{~mL}$ of diluting $\mathrm{Li}_{2} \mathrm{~S}_{6}$ solution, respectively. After standing for $12 \mathrm{~h}$, the color change of solution was observed. In addition, the supernatant solution was used for ultraviolet-visible (UV-Vis) measurement.

\subsection{Theoretical Calculation}

The calculations based-on density functional theory (DFT) were carried out using projector augmented wave (PAW) method in Vienna ab initio simulation package (VASP). The $k$-points were sampled using the Monkhorst-Pack mesh for all slab models. All models were optimized from a supercell of graphene containing $4 \times 4$-unit cells. The cut off energy for plane-wave basis set was $520 \mathrm{eV}$, and a vacuum layer of about $20 \AA$ in thickness was introduced for all the surfaces. The total energy convergence was set to be lower than $1 \times 10^{-5} \mathrm{eV}$ with the force convergence set at $0.01 \mathrm{eV} \AA^{-1}$ for geometric optimization.

\section{Results and Discussion}

\subsection{Morphological and Microstructural Characterizations}

Figure 1 schematically illustrates the synthetic route of Co- $\mathrm{N}_{4} @ 2 \mathrm{D} / 3 \mathrm{D}$ carbon composites. First, 3D architectures assembled by cross-linked 2D ZnCo-based zeolitic imidazolate framework (ZIF)-L leaves were synthesized by the coordination reaction of $\mathrm{Co}^{2+} / \mathrm{Zn}^{2+}$ ions and 2-methylimidazole ligands in water and employed as template materials. The X-ray powder diffraction patterns of the as-synthesized $\mathrm{Co} / \mathrm{Zn}$-ZIF-L matched well with that of the simulated $\mathrm{Zn}$ ZIF-L, indicating that the introduced $\mathrm{Co}^{2+}$ dopants may partially substitute the original $\mathrm{Zn}^{2+}$ ions in Zn-ZIF-L (Fig. S1). Field-emission scanning electron microscopy (FESEM) observation further showed that Co/Zn-ZIF-L architecture was constructed by cross-linked leaf-like nanosheets with a a relatively uniform dimensions and morphology (Figs. $\mathrm{S} 2$ and S3a, b). Subsequently, amorphous $\mathrm{SiO}_{2}$ was evenly

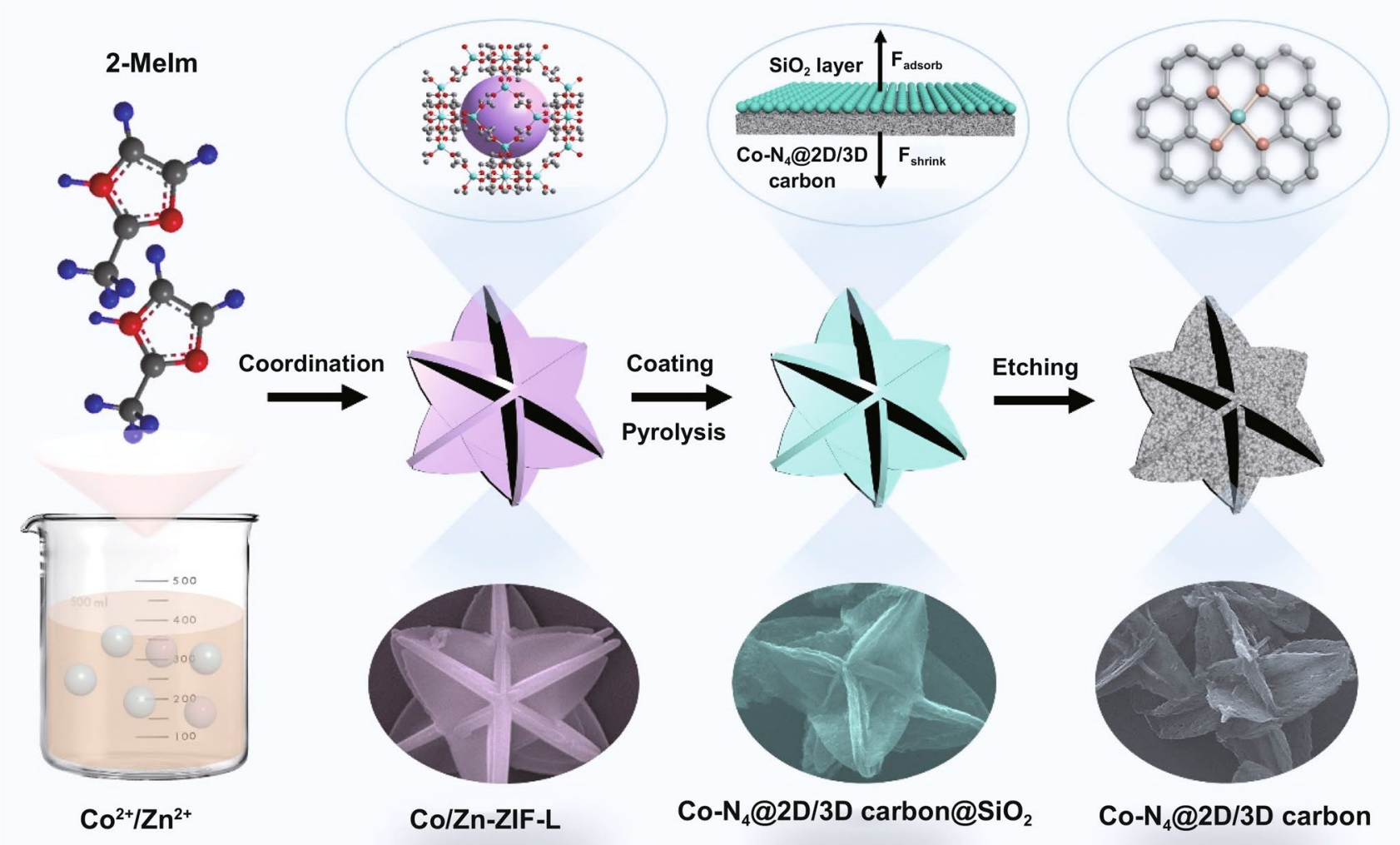

Fig. 1 Schematic synthesis procedure of $\mathrm{Co}-\mathrm{N}_{4} @ 2 \mathrm{D} / 3 \mathrm{D}$ carbon 
coated on the surface of architecture template by a hydrolysis of tetraethyl orthosilicate process to form Co/Zn-ZIF$\mathrm{L} @ \mathrm{SiO}_{2}$ core-shell particles (Fig. S4). After a pyrolysis process under flowing $\mathrm{N}_{2}$ at $930{ }^{\circ} \mathrm{C}$, the $\mathrm{Co}-\mathrm{N}_{4} @ 2 \mathrm{D} / 3 \mathrm{D}$ carbon@ $\mathrm{SiO}_{2}$ was obtained. As characterized by FESEM image in Fig. S3c and $3 d$ (Supporting Information), the $\mathrm{Co}-\mathrm{N}_{4} @ 2 \mathrm{D} / 3 \mathrm{D}$ carbon@ $\mathrm{SiO}_{2}$ sample could retain the morphology of the template except that its surface became rough and has slight shrinkage. During this process, the organic ligands liberated from Co/Zn-ZIF-L were carbonized into $\mathrm{N}$-doped porous carbon, while the low boiling-point $\mathrm{Zn}$ atoms were evaporated, and the high boiling-point Co atoms remained and were anchored on the carbon matrix. After removing the $\mathrm{SiO}_{2}$ shell using $\mathrm{HF}$, the final $\mathrm{Co}-\mathrm{N}_{4} @ 2 \mathrm{D} / 3 \mathrm{D}$ carbon was obtained. It can be observed that $\mathrm{Co}-\mathrm{N}_{4} @ 2 \mathrm{D} / 3 \mathrm{D}$ carbon remained the initial 3D structure but bestrewed with numbers of grooves and mesopores on the surface of nanosheets (Fig. S3e, f). Note that the presence of $\mathrm{SiO}_{2}$ coating not only created more pores within the carbon architecture but also could allow an anisotropic thermal shrinkage of $\mathrm{Co} / \mathrm{Zn}$-ZIF-L to preserve the configuration of template at high temperature.

For comparison, $\mathrm{Co} / \mathrm{Zn}$-ZIF-L without $\mathrm{SiO}_{2}$ coating and $\mathrm{Zn}-\mathrm{ZIF}-\mathrm{L} @ \mathrm{SiO}_{2}$ were employed as precursor to fabricate Co- $\mathrm{N}_{4} @$ carbon and 2D carbon leaves, respectively. As shown in Fig. S5a, b, Co- $\mathrm{N}_{4} @$ carbon was aggregated, and no obvious pores could be observed on its surface. Figure S6a, $b$ shows the FESEM images of 2D carbon leaves, from which porous nanosheets stacked together.

The microstructure of the obtained samples was further investigated by transmission electron microscope (TEM). As shown in Fig. 2a, the $\mathrm{Co}-\mathrm{N}_{4} @ 2 \mathrm{D} / 3 \mathrm{D}$ carbon displayed a $3 \mathrm{D}$ architecture assembled by cross-linked $2 \mathrm{D}$ porous carbon leaves, while Co- $\mathrm{N}_{4} @$ carbon showed an irregular morphology without obvious pores (Fig. S5c, d). The implanted Co single atoms in $\mathrm{Co}-\mathrm{N}_{4} @ 2 \mathrm{D} / 3 \mathrm{D}$ carbon were verified by atomic-resolution high angle annular dark-field scanning transmission electron microscope (HAADF-STEM). As shown in Fig. 2b, c, dense isolated bright dots could be observed, meaning that high-density single Co atoms homogeneously distributed in 2D/3D porous carbon. The energydispersive spectroscopy (EDS) results shown in Fig. $2 d-g$ revealed the uniform distribution of $\mathrm{C}, \mathrm{N}$ and Co elements within the $3 \mathrm{D}$ architecture framework. The Co contents in the Co- $\mathrm{N}_{4} @ 2 \mathrm{D} / 3 \mathrm{D}$ carbon and $\mathrm{Co}-\mathrm{N}_{4} @$ carbon were about $1.01 \%$ and $1.33 \%$, respectively, according to the inductively coupled plasma-optical emission spectroscopy (ICP-OES) results.

\subsection{Phase, Coordination Environment and Surface Property Characterizations}

Figure $\mathrm{S} 7$ shows the XRD patterns of $\mathrm{Co}-\mathrm{N}_{4} @ 2 \mathrm{D} / 3 \mathrm{D}$ carbon and $\mathrm{Co}-\mathrm{N}_{4} @$ carbon, in which no characteristics peaks for Co species were found, revealing that Co is atomically dispersed rather than aggregated nanoparticles on them. The chemical states and local environment of Co sites for $\mathrm{Co}-\mathrm{N}_{4} @ 2 \mathrm{D} / 3 \mathrm{D}$ carbon were analyzed by synchrotron-based X-ray absorption near-edge structure (XANES) spectroscopy and extended X-ray absorption fine structure (EXAFS) spectroscopy. The XANES spectra of Co K-edge show a nearedge absorption energy of $\mathrm{Co}-\mathrm{N}_{4} @ 2 \mathrm{D} / 3 \mathrm{D}$ carbon located between those of the Co foil and $\mathrm{CoO}$ (Fig. 2h), implying that Co single atoms carried positive charges [35, 36]. The $k_{2}$-weighted Fourier transforms (FT) of the extended EXAFS in Fig. 2i demonstrated a main peak at $1.4 \AA$ for $\mathrm{Co}-\mathrm{N}_{4} @ 2 \mathrm{D} / 3 \mathrm{D}$ carbon, which was attributed to $\mathrm{Co}-\mathrm{N}$ scattering path $[37,38]$. The absence of longer $\mathrm{Co}-\mathrm{Co}$ backscattering paths in the spectra of $\mathrm{Co}-\mathrm{N}_{4} @ 2 \mathrm{D} / 3 \mathrm{D}$ carbon further suggests the atomic dispersion of Co atoms, in line with the STEM founding. The quantitative structural parameters of Co in the Co- $\mathrm{N}_{4} @ 2 \mathrm{D} / 3 \mathrm{D}$ carbon were determined by leastsquares EXAFS fitting shown in Fig. $2 \mathrm{j}$ and Table $\mathrm{S} 1$. The best fitting result for the first shell indicates that each Co atom is likely coordinated by four nitrogen atoms, suggesting a Co- $\mathrm{N}_{4}$ configuration for the Co-N bonding [39, 40].

The pore structure of samples was investigated by nitrogen sorption isotherms. As shown in Fig. 3a, b, Co- $\mathrm{N}_{4} @ 2 \mathrm{D} / 3 \mathrm{D}$ carbon exhibited a high Brunauer-Emmett-Teller (BET) surface area of 482 $\mathrm{m}^{2} \mathrm{~g}^{-1}$ and large pore volume of $0.649 \mathrm{~cm}^{3} \mathrm{~g}^{-1}$, which were similar with those of 2D carbon $\left(534 \mathrm{~m}^{2} \mathrm{~g}^{-1}\right.$ and 0.641 $\mathrm{cm}^{3} \mathrm{~g}^{-1}$ ) but significantly larger than those of $\mathrm{Co}-\mathrm{N}_{4} @$ carbon $\left(198 \mathrm{~m}^{2} \mathrm{~g}^{-1}\right.$ and $\left.0.117 \mathrm{~cm}^{3} \mathrm{~g}^{-1}\right)$. The above results illustrated that the introduction of $\mathrm{SiO}_{2}$ would prevent the stacking of 2D carbon leaves during thermal treatment and was favorable to higher pore volume, which are consistent with FESEM observations. Additionally, the implanted atomically dispersed $\mathrm{Co}-\mathrm{N}_{4}$ in $\mathrm{Co}-\mathrm{N}_{4} @ 2 \mathrm{D} / 3 \mathrm{D}$ carbon may not block the formation of mesoporous structure and have a negligible effect on the surface area of composites. 

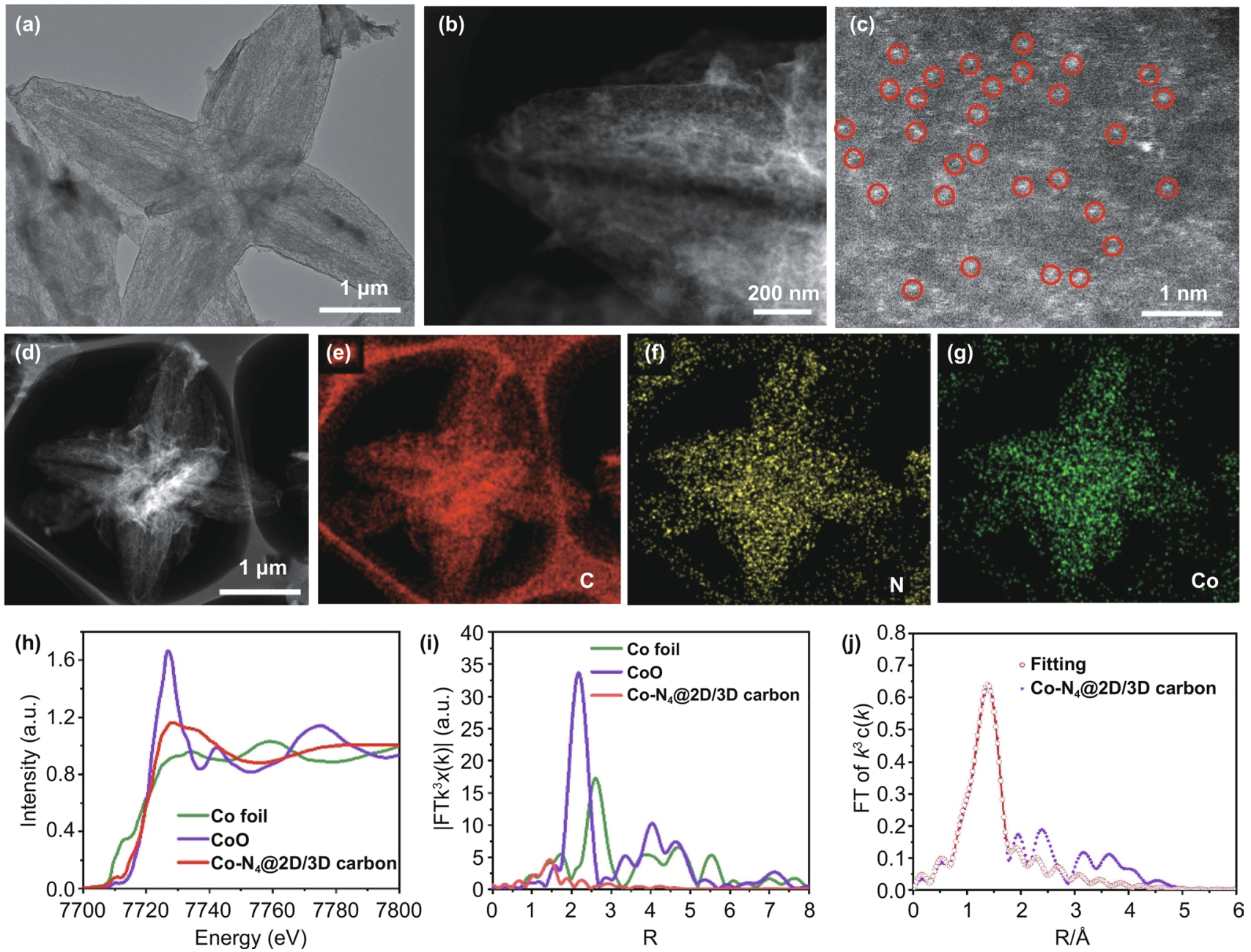

Fig. 2 a TEM image, b-d HAADF-STEM images of Co- $\mathrm{N}_{4} @ 2 \mathrm{D} / 3 \mathrm{D}$ carbon and e-g corresponding element mapping of C, N and Co in Co$\mathrm{N}_{4} @ 2 \mathrm{D} / 3 \mathrm{D}$ carbon. h Co K-edge XANES spectra and i Fourier transform (FT) of the Co-K-edge for Co-N $\mathrm{N}_{4} @ 2 \mathrm{D} / 3 \mathrm{D}$ carbon, CoO and Co foil. $\mathbf{j}$ The corresponding EXAFS $\mathrm{r}$ space fitting curve of $\mathrm{Co}-\mathrm{N}_{4} @ 2 \mathrm{D} / 3 \mathrm{D}$ carbon

The high specific surface area of $\mathrm{Co}-\mathrm{N}_{4} @ 2 \mathrm{D} / 3 \mathrm{D}$ carbon composites provide rich electrochemical active interfaces to accelerate the sulfur redox reaction, while the large pore volume is benefiting to accommodating the sulfur species and buffering the volume variation. Encouraged by the chemical and microstructure traits, the Co- $\mathrm{N}_{4} @ 2 \mathrm{D} / 3 \mathrm{D}$ carbon composite was employed as sulfur host to fabricate $\mathrm{S} @ \mathrm{Co}-\mathrm{N}_{4} @ 2 \mathrm{D} / 3 \mathrm{D}$ carbon composites through a melt-diffusion method. After sulfur infiltration, the diffraction peaks of sulfur can be identified in the XRD patterns of $\mathrm{S} @ \mathrm{Co}-\mathrm{N}_{4} @ 2 \mathrm{D} / 3 \mathrm{D}$ carbon composites (Fig. 3c). The sulfur content of $\mathrm{S} @ \mathrm{Co}-\mathrm{N}_{4} @ 2 \mathrm{D} / 3 \mathrm{D}$ carbon composites is measured to be $73 \mathrm{wt} \%$ by the thermogravimetric analysis (TGA), while the sulfur content of S@Co- $\mathrm{N}_{4} @$ carbon composites through the same melt-diffusion process is only $65.6 \%$, further signifying the advantages of $\mathrm{Co}-\mathrm{N}_{4} @ 2 \mathrm{D} / 3 \mathrm{D}$ carbon host (Fig. 3d). FESEM image in Fig. 3e showed that the obtained S@Co-N $\mathrm{N}_{4} @ 2 \mathrm{D} / 3 \mathrm{D}$ carbon composite preserves the initial 3D architecture morphology and there is no any aggregation of sulfur particles on its surface. Meanwhile, the corresponding elements mapping revealed a homogeneous distribution of $\mathrm{C}, \mathrm{N}$, $\mathrm{Co}$ and $\mathrm{S}$ element within the architecture, illustrating the full incorporation of sulfur into the $\mathrm{Co}-\mathrm{N}_{4} @ 2 \mathrm{D} / 3 \mathrm{D}$ carbon host (Fig. 3f). 

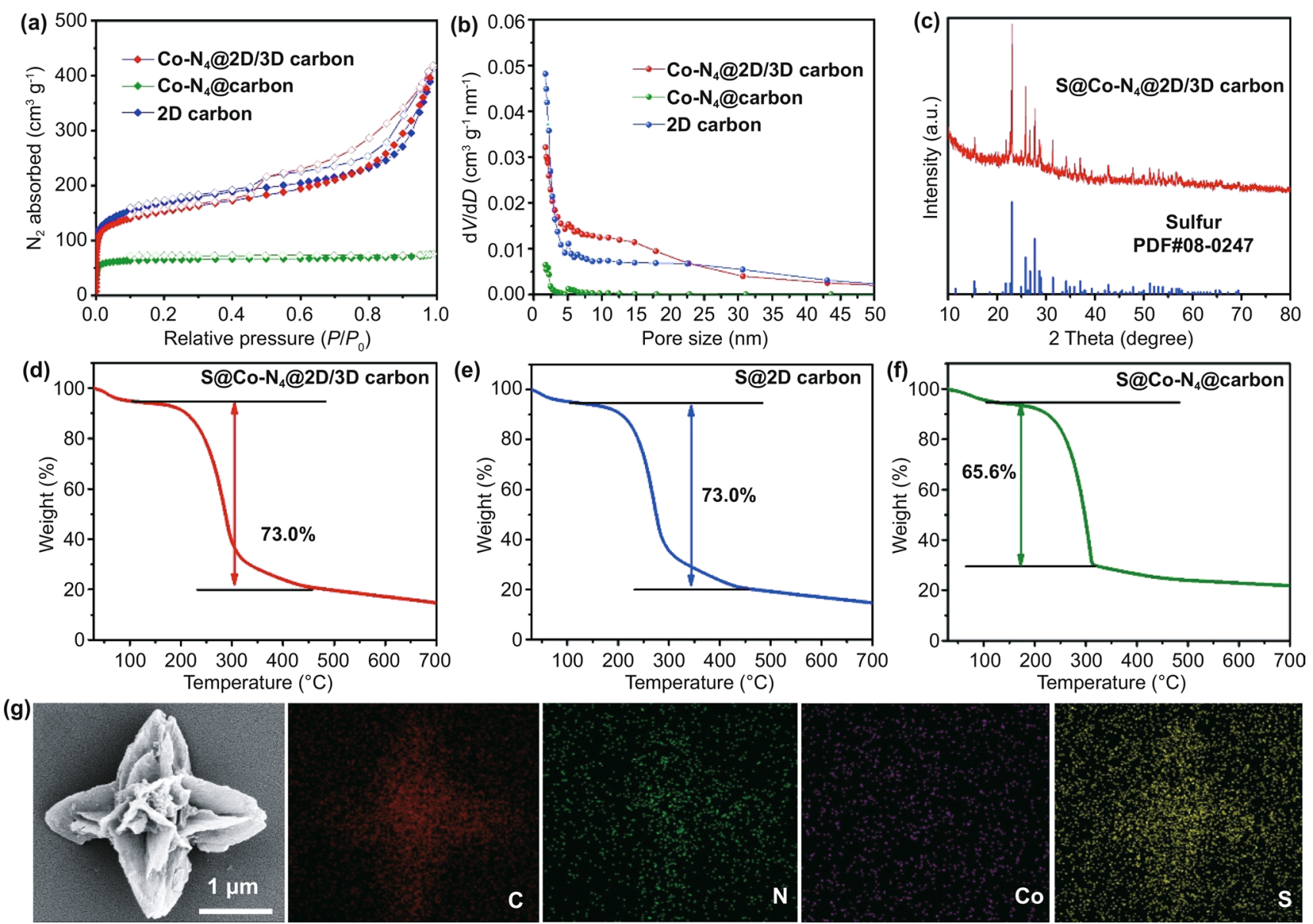

Fig. 3 a $\mathrm{N}_{2}$ sorption isotherms based on the Barrett-Joyner-Halenda (BJH) method and $\mathbf{b}$ the pores distribution of Co- $\mathrm{N}_{4} @ 2 \mathrm{D} / 3 \mathrm{D}$ carbon, Co$\mathrm{N}_{4} @$ carbon and 2D carbon. $\mathbf{c}$ XRD pattern of S@Co- $\mathrm{N}_{4} @ 2 \mathrm{D} / 3 \mathrm{D}$ carbon. TGA curves of $\mathbf{d} \mathrm{S} @ \mathrm{Co}-\mathrm{N}_{4} @ 2 \mathrm{D} / 3 \mathrm{D}$ carbon, e S@2D carbon and $\mathbf{f}$ $\mathrm{S} @ \mathrm{Co}-\mathrm{N}_{4} @$ carbon. g FESEM image of $\mathrm{S} @ \mathrm{Co}-\mathrm{N}_{4} @ 2 \mathrm{D} / 3 \mathrm{D}$ carbon composites and corresponding elements mapping images of $\mathrm{C}, \mathrm{N}, \mathrm{Co}$ and $\mathrm{S}$

\subsection{Adsorption Ability and Catalytic Effect}

To investigate the adsorption properties of $\mathrm{Co}-\mathrm{N}_{4} @ 2 \mathrm{D} / 3 \mathrm{D}$ carbon with the LiPS, visualized absorption experiments were performed by adding Co- $\mathrm{N}_{4} @ 2 \mathrm{D} / 3 \mathrm{D}$ carbon, Co- $\mathrm{N}_{4} @$ carbon, and $2 \mathrm{D}$ carbon into an as-prepared $\mathrm{Li}_{2} \mathrm{~S}_{6}$ solution. After $12 \mathrm{~h}$, the $\mathrm{Li}_{2} \mathrm{~S}_{6}$ solution containing Co- $\mathrm{N}_{4} @ 2 \mathrm{D} / 3 \mathrm{D}$ carbon became almost colorless, while the light-yellow color only slightly faded in the reference $\mathrm{Li}_{2} \mathrm{~S}_{6}$ solution containing Co- $\mathrm{N}_{4} @$ carbon and 2D carbon (Fig. 4a inset), indicating a strong trapping capability of $\mathrm{Co}-\mathrm{N}_{4} @ 2 \mathrm{D} / 3 \mathrm{D}$ carbon for long-chain LiPSs. The concentration changes of LiPSs after adding samples were further analyzed by ultraviolet-visible (UV) absorption. The $\mathrm{S}_{6}{ }^{2-}$ species for $\mathrm{Co}-\mathrm{N}_{4} @ 2 \mathrm{D} / 3 \mathrm{D}$ carbon exhibited a much lower peak intensity compared with other samples, which is consistent with the result of
LiPS adsorption test (Fig. 4a). To further study the chemical interaction between Co- $\mathrm{N}_{4} @ 2 \mathrm{D} / 3 \mathrm{D}$ carbon and $\mathrm{Li}_{2} \mathrm{~S}_{6}, \mathrm{XPS}$ characterizations were conducted on the $\mathrm{Co}-\mathrm{N}_{4} @ 2 \mathrm{D} / 3 \mathrm{D}$ carbon and $\mathrm{Li}_{2} \mathrm{~S}_{6}$ before and after adsorption. As shown in Fig. 4b, after adsorbing $\mathrm{Li}_{2} \mathrm{~S}_{6}$, the peaks of Co $2 p 3 / 2$ located at 780.45 and $785.92 \mathrm{eV}$ shift to higher binding energy centered at 780.74 and $786.46 \mathrm{eV}$, respectively, while two Co $2 p 1 / 2$ peaks at 795.64 and 803.12 shift to $796.33 \mathrm{eV}$ and $804.44 \mathrm{eV}$, respectively, revealing that the electron transfer from $\mathrm{Li}_{2} \mathrm{~S}_{6}$ to $\mathrm{Co}[11,41]$. Moreover, $\mathrm{Li} 1 \mathrm{~s}$ peak of Co- $\mathrm{N}_{4} @ 2 \mathrm{D} / 3 \mathrm{D}$ carbon- $\mathrm{Li}_{2} \mathrm{~S}_{6}$ shifts $0.39 \mathrm{eV}$ toward higher binding energy, accompanied with an additional peak (57.9 eV) (Fig. 4c), indicating the formation of Li-N bond $[42,43]$. These results demonstrate that $\mathrm{Co}-\mathrm{N}_{4} @ 2 \mathrm{D} / 3 \mathrm{D}$ carbon can effectively escape soluble LiPSs into the electrolyte and ameliorate weight loss of active species. 

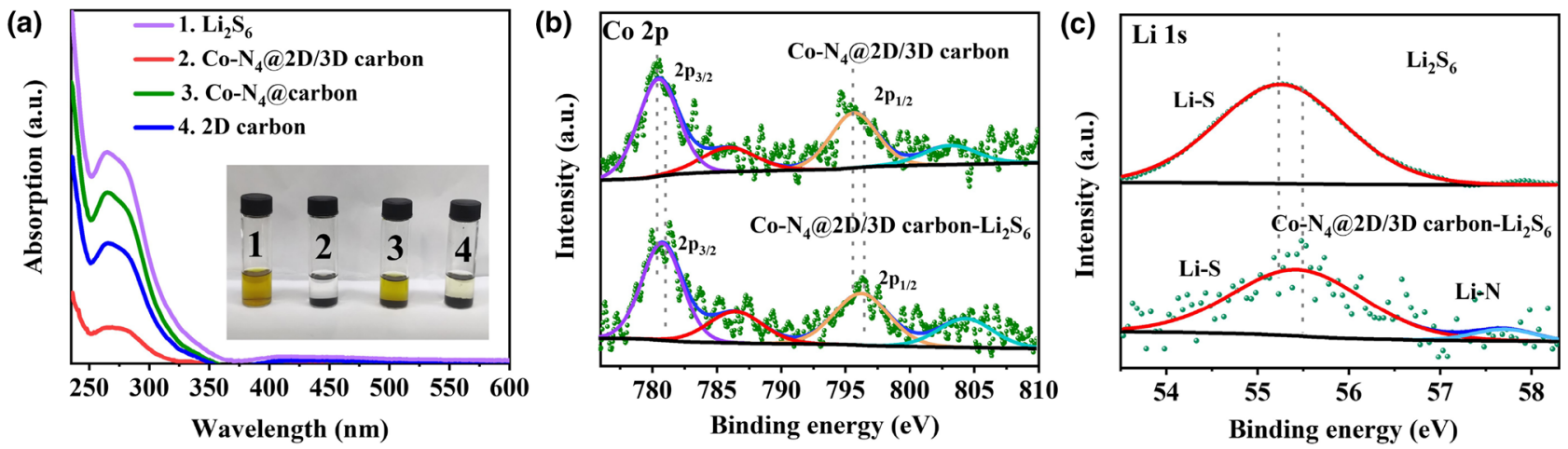

(d)
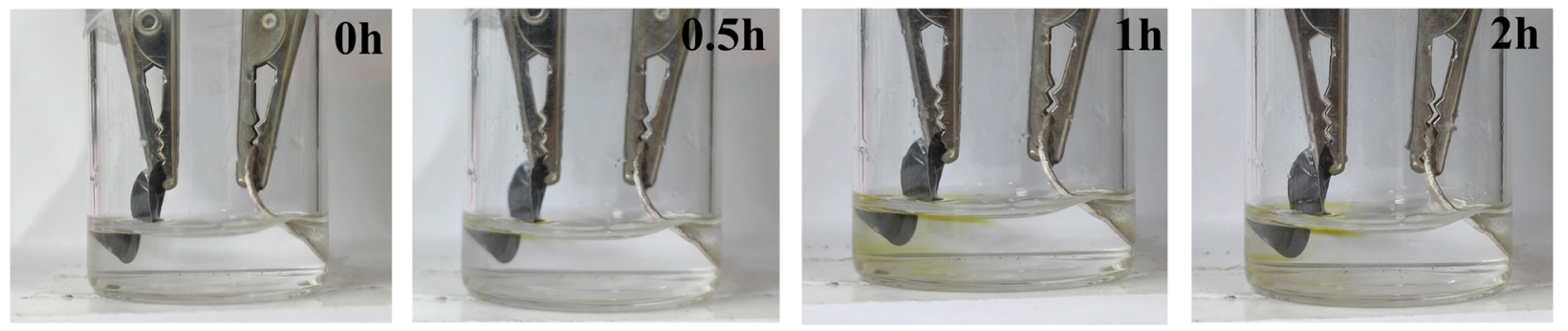

(e)
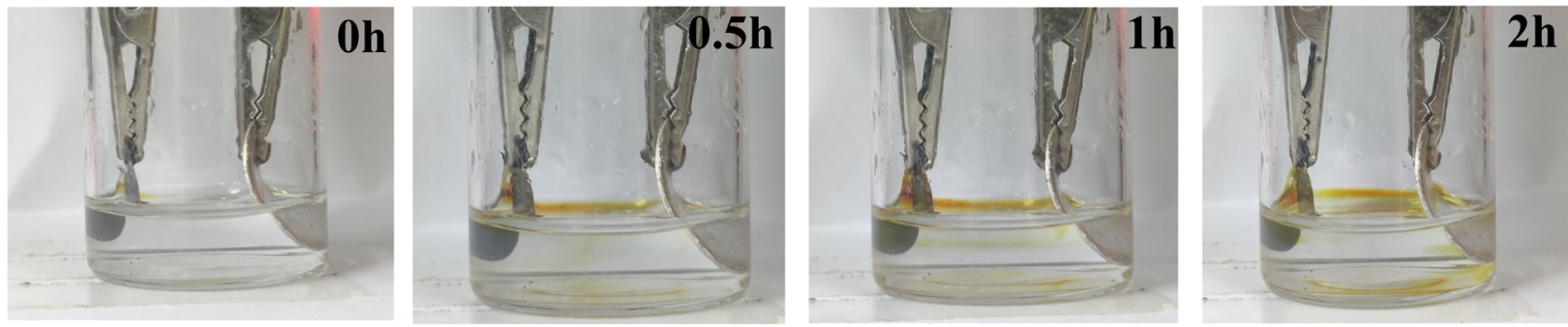

(f)
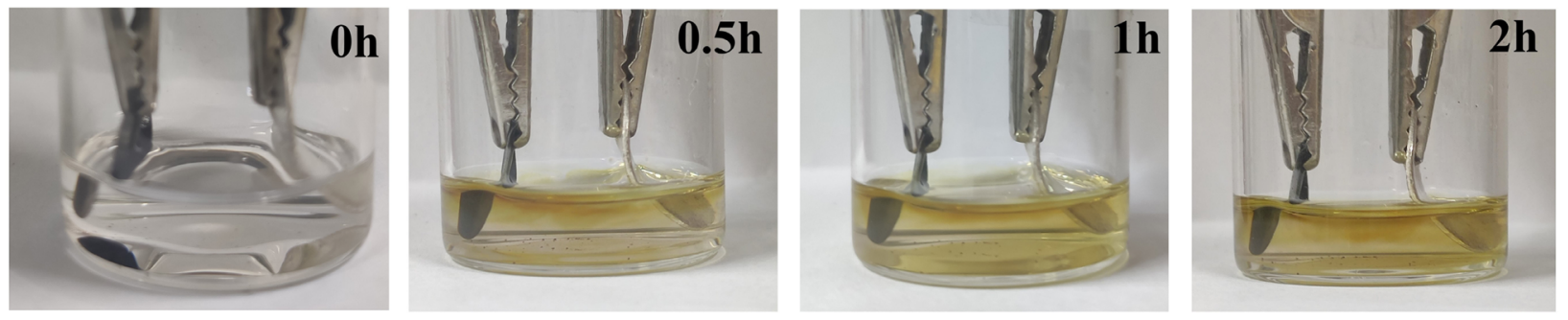

Fig. 4 a UV-Vis absorption spectra and optical images of pure $\mathrm{Li}_{2} \mathrm{~S}_{6}$ solutions as well as the $\mathrm{Li}_{2} \mathrm{~S}_{6}$ solutions trapped by Co-N $\mathrm{N}_{4} @ 2 \mathrm{D} / 3 \mathrm{D}$ carbon, Co- $\mathrm{N}_{4} @$ carbon and 2D carbon. b The Co $2 p$ XPS of spectra of Co- $\mathrm{N}_{4} @ 2 \mathrm{D} / 3 \mathrm{D}$ before and after adsorbing Li $\mathrm{S}_{6}$. c the Li $1 s$ XPS spectra of $\mathrm{Li}_{2} \mathrm{~S}_{6}$ before and after been adsorbed with $\mathrm{Co}-\mathrm{N}_{4} @ 2 \mathrm{D} / 3 \mathrm{D}$ carbon. In-situ beaker cell observation during discharging from 2.8 to $1.7 \mathrm{~V}$ at $0.1 \mathrm{C}$ for $\mathbf{d} \mathrm{S} @ \mathrm{Co}-\mathrm{N}_{4} @ 2 \mathrm{D} / 3 \mathrm{D}$ carbon, e S@2D carbon, and f S@Co- $\mathrm{N}_{4} @$ carbon

An in-situ beaker cell observation experiment was also conducted to study the polysulfides diffusion in electrolyte for S@Co- $\mathrm{N}_{4} @ 2 \mathrm{D} / 3 \mathrm{D}$ carbon, S@2D carbon and S@ $\mathrm{Co}-\mathrm{N}_{4} @$ carbon during electrochemical reaction. The assembled cell was first discharged at 0.1 C. As shown in Fig. 4e, f, the color of electrolyte in the S@2D carbon- and S@ Co- $\mathrm{N}_{4} @$ carbon-based cell changed from colorless to yellow with the reaction going on, implying the severe dissolution of LiPSs intermediates into electrolyte before transforming into insoluble $\mathrm{Li}_{2} \mathrm{~S}$. In contrast, the color of electrolyte in the $\mathrm{S} @ \mathrm{Co}-\mathrm{N}_{4} @ 2 \mathrm{D} / 3 \mathrm{D}$ carbon-based cell underwent a negligible change (Fig. 4d), illustrating the strong absorptivity of Co- $\mathrm{N}_{4} @ 2 \mathrm{D} / 3 \mathrm{D}$ carbon for dissoluble LiPSs.

To reveal the catalytic effect of Co- $\mathrm{N}_{4} @ 2 \mathrm{D} / 3 \mathrm{D}$ carbon on enhancing the kinetics of LiPSs conversion in the Li-S battery, cyclic voltammetry (CV) measurements were carried 
out in the voltage from -1 to $1 \mathrm{~V}$ for the symmetric cells with using Co- $\mathrm{N}_{4} @ 2 \mathrm{D} / 3 \mathrm{D}$ carbon as both work and counter electrodes and $0.2 \mathrm{M} \mathrm{Li}_{2} \mathrm{~S}_{6}$ as the electrolyte. As shown in Fig. 5a, Co- $\mathrm{N}_{4} @ 2 \mathrm{D} / 3 \mathrm{D}$ carbon electrode exhibited a stronger peak current density and voltage hysteresis than the $\mathrm{Co}-\mathrm{N}_{4} @$ carbon and 2D carbon electrodes, indicating the higher electrochemical reversibility and better catalytic reaction kinetics of the Co- $\mathrm{N}_{4} @ 2 \mathrm{D} / 3 \mathrm{D}$ carbon. The excellent catalytic activity could be further confirmed by linear sweep voltammetry (LSV) tests. As shown in Fig. 5b, the intensity of peak corresponding to the conversion reaction from $\mathrm{Li}_{2} \mathrm{~S}_{4}$ to $\mathrm{Li}_{2} \mathrm{~S}$ for $\mathrm{Co}-\mathrm{N}_{4} @ 2 \mathrm{D} / 3 \mathrm{D}$ carbon was larger those of $\mathrm{Co}-\mathrm{N}_{4} @$ carbon and 2D carbon, indicating its superior reaction kinetics. Meanwhile, the Tafel plots derived from this reaction (marked by the purple liner in Fig. 5b) reveal the smallest Tafel slope ( $38 \mathrm{mV} \mathrm{dec}^{-1}$ ) for Co- $\mathrm{N}_{4} @ 2 \mathrm{D} / 3 \mathrm{D}$ carbon compared with those for Co- $\mathrm{N}_{4} @$ carbon $\left(54 \mathrm{mV} \mathrm{dec}{ }^{-1}\right.$ ) and $2 \mathrm{D}$ carbon $\left(51 \mathrm{mV} \mathrm{dec}^{-1}\right)$ (Fig. $\left.5 \mathrm{c}\right)$, indicated that the enhancement in sulfur reaction kinetics can be ascribed to the hierarchical architecture, which provides more accessible active sites to accelerate the conversion from $\mathrm{Li}_{2} \mathrm{~S}_{4}$ to $\mathrm{Li}_{2} \mathrm{~S}$ and thus improves the utilization of sulfur.

A potentiostatic nucleation measurement was conducted to further demonstrate the advantage of Co- $\mathrm{N}_{4} @ 2 \mathrm{D} / 3 \mathrm{D}$ for the conversion from liquid LiPSs to solid $\mathrm{Li}_{2} \mathrm{~S}$ through using identical carbon fibers loaded with $\mathrm{Co}-\mathrm{N}_{4} @ 2 \mathrm{D} / 3 \mathrm{D}$ carbon, Co- $\mathrm{N}_{4} @$ carbon and 2D carbon electrodes. As shown in Fig. S8 (Supporting Information), the capacities of $\mathrm{Li}_{2} \mathrm{~S}$ precipitation on $\mathrm{Co}-\mathrm{N}_{4} @ 2 \mathrm{D} / 3 \mathrm{D}$ carbon, $\mathrm{Co}-\mathrm{N}_{4} @$ carbon and 2D carbon were calculated to be 217.01, 163.19, and $182.07 \mathrm{mAh} \mathrm{g}^{-1}$, respectively, manifesting the highest catalytic activity of Co- $\mathrm{N}_{4} @ 2 \mathrm{D} / 3 \mathrm{D}$ carbon toward $\mathrm{Li}_{2} \mathrm{~S}$ precipitation. The CV curves of $\mathrm{S} @ \mathrm{Co}-\mathrm{N}_{4} @ 2 \mathrm{D} / 3 \mathrm{D}$ carbon, S@Co- $\mathrm{N}_{4} @$ carbon and S@2D carbon cathodes at different scan rates $\left(0.1-0.6 \mathrm{mV} \mathrm{s}^{-1}\right)$ were shown in Fig. S9a, c and e. The well-separated cathodic/anodic peaks with a larger current density reveal the mitigated electrochemical polarization of the $\mathrm{S} @ \mathrm{Co}-\mathrm{N}_{4} @ 2 \mathrm{D} / 3 \mathrm{D}$ carbon in comparison with other electrodes. Accordingly, a linear relationship between the anodic and cathodic peak currents and square root was also investigated (Fig. S9b, d and
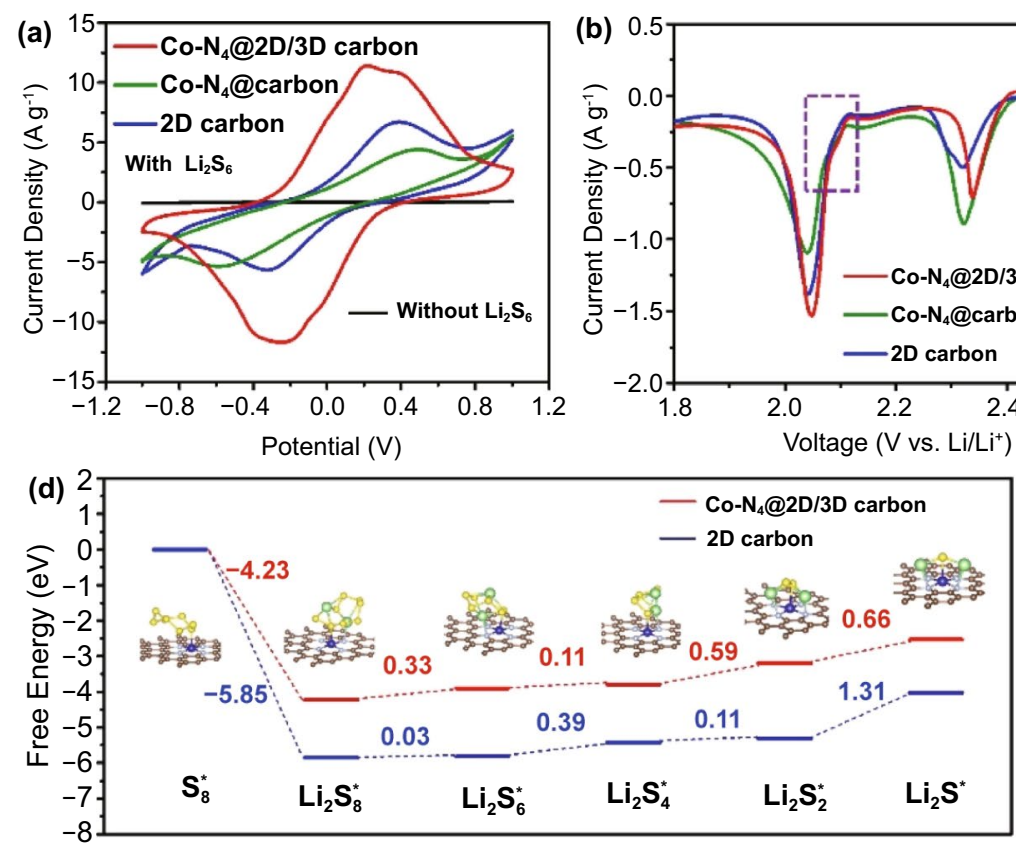

Reaction Coordinate
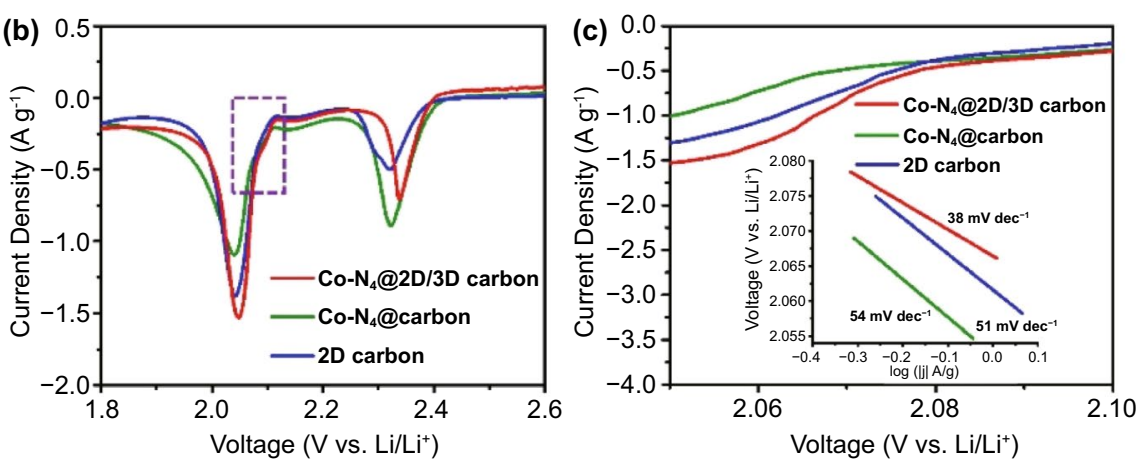

(e)

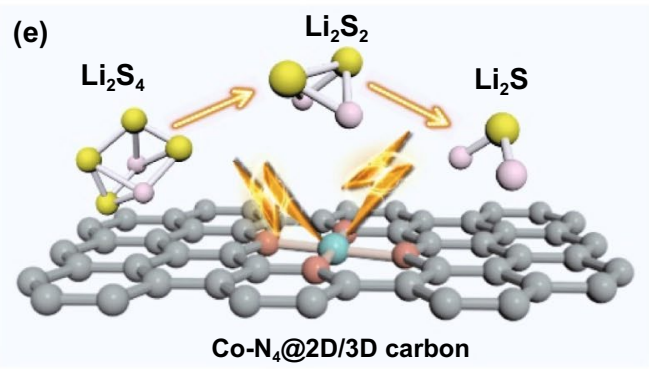

Fig. 5 a CV curves of symmetric cells from -1 to $1 \mathrm{~V}$ and b LSV curves between 1.7 and $2.8 \mathrm{~V}$ at a scan rate of $0.1 \mathrm{mV} \mathrm{s} \mathrm{s}^{-1}$ with the Co$\mathrm{N}_{4} @ 2 \mathrm{D} / 3 \mathrm{D}$ carbon, Co- $\mathrm{N}_{4} @$ carbon and 2D carbon electrodes. c Potentiostatic polarization curves from the LSV measurements and the inset showing the derived Tafel plots. d Energy profiles for the reduction of LiPSs on Co- $\mathrm{N}_{4} @ 2 \mathrm{D} / 3 \mathrm{D}$ carbon and 2D carbon substrates, the inset showing the optimized adsorption conformations of intermediate species on $\mathrm{Co}_{-} \mathrm{N}_{4} @ 2 \mathrm{D} / 3 \mathrm{D}$ carbon and 2D carbon substrates. f Schematic illustration of the catalysis effect of $\mathrm{Co}-\mathrm{N}_{4} @ 2 \mathrm{D} / 3 \mathrm{D}$ carbon toward LiPSs 
f), suggesting the diffusion-limited process of cathodes. Moreover, according to the fitting of this linear dependence, $\mathrm{Li}^{+}$diffusion coefficient $(D)$ can be calculated using the Randles-Sevcik equation [44, 45]:

$I_{\mathrm{p}}=\left(2.69 \times 10^{5}\right) \times n^{1.5} A D^{0.5} C v^{0.5}$

where $I_{\mathrm{p}}$ represents the peak current density (A), $n$ is the number of transferred charges, $A$ is the area of the electrode $\left(\mathrm{cm}^{2}\right), C$ is the concentration of lithium ions in the electrolyte $\left(\mathrm{mol} \mathrm{cm}^{-3}\right)$, and $\nu$ is the scan rate $\left(\mathrm{V} \mathrm{s}^{-1}\right)$. The values of $D$ for $\mathrm{S} @ \mathrm{Co}-\mathrm{N}_{4} @ 2 \mathrm{D} / 3 \mathrm{D}$ carbon at peaks 1,2 , and 3 are calculated to be $3.20 \times 10^{-8}, 3.88 \times 10^{-8}$, and $1.06 \times 10^{-7} \mathrm{~cm}^{2} \mathrm{~s}^{-1}$, respectively, which are higher than those of S@Co- $\mathrm{N}_{4} @$ carbon and S@2D carbon cathodes, suggesting the facilitated ion transfer of $\mathrm{S} @$ $\mathrm{Co}-\mathrm{N}_{4} @ 2 \mathrm{D} / 3 \mathrm{D}$ carbon.

The improved reaction kinetics and chemical interaction between the $\mathrm{S} @ \mathrm{Co}-\mathrm{N}_{4} @ 2 \mathrm{D} / 3 \mathrm{D}$ carbon cathode and LiPS could be further understood by first-principles calculations. The optimized configurations of $\mathrm{Co}-\mathrm{N}_{4} @ 2 \mathrm{D} / 3 \mathrm{D}$ carbon and 2D carbon were shown in Fig. S10. As shown in Fig. S11, the Co- $\mathrm{N}_{4} @ 2 \mathrm{D} / 3 \mathrm{D}$ carbon has much higher adsorption energy for $\mathrm{Li}_{2} \mathrm{~S}_{4}$ and $\mathrm{Li}_{2} \mathrm{~S}_{6}(-0.927$ and $-0.904 \mathrm{eV})$ than $2 \mathrm{D}$ carbon $(-0.366$ and $-0.274 \mathrm{eV})$. Figure 5d displays the calculated Gibbs free energy of the different possible reactions from $\mathrm{S}_{8}$ to $\mathrm{Li}_{2} \mathrm{~S}$ on the Co- $\mathrm{N}_{4} @ 2 \mathrm{D} / 3 \mathrm{D}$ carbon and 2D/3D carbon during the electrochemical process [46, 47]. It can be found that the conversion from $\mathrm{S}_{8}$ to $\mathrm{Li}_{2} \mathrm{~S}_{8}$ is exothermic and occurs spontaneous, while the subsequent four reduction steps for the formation of $\mathrm{Li}_{2} \mathrm{~S}_{6}, \mathrm{Li}_{2} \mathrm{~S}_{4}, \mathrm{Li}_{2} \mathrm{~S}_{2}$, and $\mathrm{Li}_{2} \mathrm{~S}$ are all endothermic. Due to the largest positive Gibbs energy barrier, the conversion from $\mathrm{Li}_{2} \mathrm{~S}_{2}$ to $\mathrm{Li}_{2} \mathrm{~S}$ is the rate-determining step in the whole process $[32,48]$. For this rate-determining step, the Gibbs free energy of $\mathrm{Co}-\mathrm{N}_{4} @ 2 \mathrm{D} / 3 \mathrm{D}$ carbon support is $0.66 \mathrm{eV}$, much lower than that of $2 \mathrm{D}$ carbon support $(1.31 \mathrm{eV})$, suggesting that the reduction in sulfur is thermodynamically more favorable on $\mathrm{Co}-\mathrm{N}_{4} @ 2 \mathrm{D} / 3 \mathrm{D}$ carbon than on $2 \mathrm{D}$ carbon. Figure $5 \mathrm{e}$ schematically illustrated the catalysis effect of $\mathrm{Co}-\mathrm{N}_{4} @ 2 \mathrm{D} / 3 \mathrm{D}$ carbon toward lithium polysulfides, from which fully accessible $\mathrm{Co}-\mathrm{N}_{4}$ sites implanted within 2D/3D carbon framework can significantly facilitate the redox reaction from $\mathrm{Li}_{2} \mathrm{~S}_{4}$ to $\mathrm{Li}_{2} \mathrm{~S}$ and thus dramatically enhance the electrochemical performance of sulfur cathodes.

\subsection{Electrochemical Performance Evaluation}

To systematically evaluate the electrochemical performance of the S@Co-N $\mathrm{N}_{4} @ 2 \mathrm{D} / 3 \mathrm{D}$ carbon cathode, coin-type Li-S batteries were assembled. The galvanostatic charge-discharge profiles of $\mathrm{S} @ \mathrm{Co}-\mathrm{N}_{4} @ 2 \mathrm{D} / 3 \mathrm{D}$ carbon as well as contrastive samples were first investigated. As shown in Fig. 6a, all cathodes display two discharge plateaus about at 2.3 and $2.1 \mathrm{~V}$ in discharge process, which could be ascribed to the electroreduction of $\mathrm{S}_{8}$ into long-chain LiPSs $\left(\mathrm{Li}_{2} \mathrm{~S}_{8}\right.$ and $\mathrm{Li}_{2} \mathrm{~S}_{6}$ ) and further reduction in the LiPSs to $\mathrm{Li}_{2} \mathrm{~S}_{2}$ and $\mathrm{Li}_{2} \mathrm{~S}[49,50]$. Nevertheless, the $\mathrm{S} @ \mathrm{Co}-\mathrm{N}_{4} @ 2 \mathrm{D} / 3 \mathrm{D}$ carbon cathode displayed the highest discharge capacity and the smallest potential polarization. Meanwhile, the CVs of S@ Co- $\mathrm{N}_{4} @ 2 \mathrm{D} / 3 \mathrm{D}$ carbon, S@Co- $\mathrm{N}_{4} @$ carbon and S@2D carbon cathodes were collected within a potential window of $1.7-2.8 \mathrm{~V}$ at a scan rate of $0.1 \mathrm{mV} \mathrm{s}^{-1}$ (Fig. S12). It is observed that the $\mathrm{S} @ \mathrm{Co}-\mathrm{N}_{4} @ 2 \mathrm{D} / 3 \mathrm{D}$ carbon displays higher peak intensity and lower voltage gap than contrast electrodes. These results suggest the fastest conversion kinetics for LiPS because of the high affinity and catalytic activity of Co- $\mathrm{N}_{4} @ 2 \mathrm{D} / 3 \mathrm{D}$ carbon.

The rate performance of $\mathrm{S} @ \mathrm{Co}-\mathrm{N}_{4} @ 2 \mathrm{D} / 3 \mathrm{D}$ carbon, S@ $\mathrm{Co}-\mathrm{N}_{4} @$ carbon and $\mathrm{S} @ 2 \mathrm{D}$ carbon electrodes were assessed under various current rates from 0.2 to $5 \mathrm{C}$ with an electrolytes/sulfur (E/S) ratio of $15 \mu \mathrm{L} \mathrm{mg}^{-1}$. As shown in Fig. 6b, when the current densities are $0.2 \mathrm{C}, 0.5 \mathrm{C}, 1 \mathrm{C}, 2 \mathrm{C}$, and 5 $\mathrm{C}$, the average specific capacities of the $\mathrm{S} @ \mathrm{Co}-\mathrm{N}_{4} @ 2 \mathrm{D} / 3 \mathrm{D}$ carbon cathode are 1171, 1015, 909, 805, and $695 \mathrm{mAh} \mathrm{g}^{-1}$, respectively, much better than those of S@Co- $\mathrm{N}_{4} @$ carbon and S@2D carbon electrodes. When the current density is restored to $0.2 \mathrm{C}$, a high specific capacity of $1064 \mathrm{mAh} \mathrm{g}^{-1}$ is recovered, manifesting a superior rate capability of $\mathrm{S} @$ Co- $\mathrm{N}_{4} @ 2 \mathrm{D} / 3 \mathrm{D}$ carbon cathode [49]. Figure 6c shows the charge/discharge profiles of S@Co- $\mathrm{N}_{4} @ 2 \mathrm{D} / 3 \mathrm{D}$ carbon cathode at different current densities. With the increase in the current density, the potential difference between the charge and discharge plateaus increases gradually. However, the two well-maintained plateaus can still be observed even at $5 \mathrm{C}$, implying the fast reaction kinetics in $\mathrm{S} @ \mathrm{Co}-\mathrm{N}_{4} @ 2 \mathrm{D} / 3 \mathrm{D}$ carbon cathode. Electrochemical impedance spectroscopy (EIS) measurements of the symmetric cells were carried out to further evaluate the kinetics reactions at the electrode interface. As shown in Fig. S13, the charge transfer resistance at the S@Co- $\mathrm{N}_{4} @ 2 \mathrm{D} / 3 \mathrm{D}$ carbon cathode/polysulfide interface is smaller than those of the $\mathrm{S} @ \mathrm{Co}-\mathrm{N}_{4} @$ carbon and 

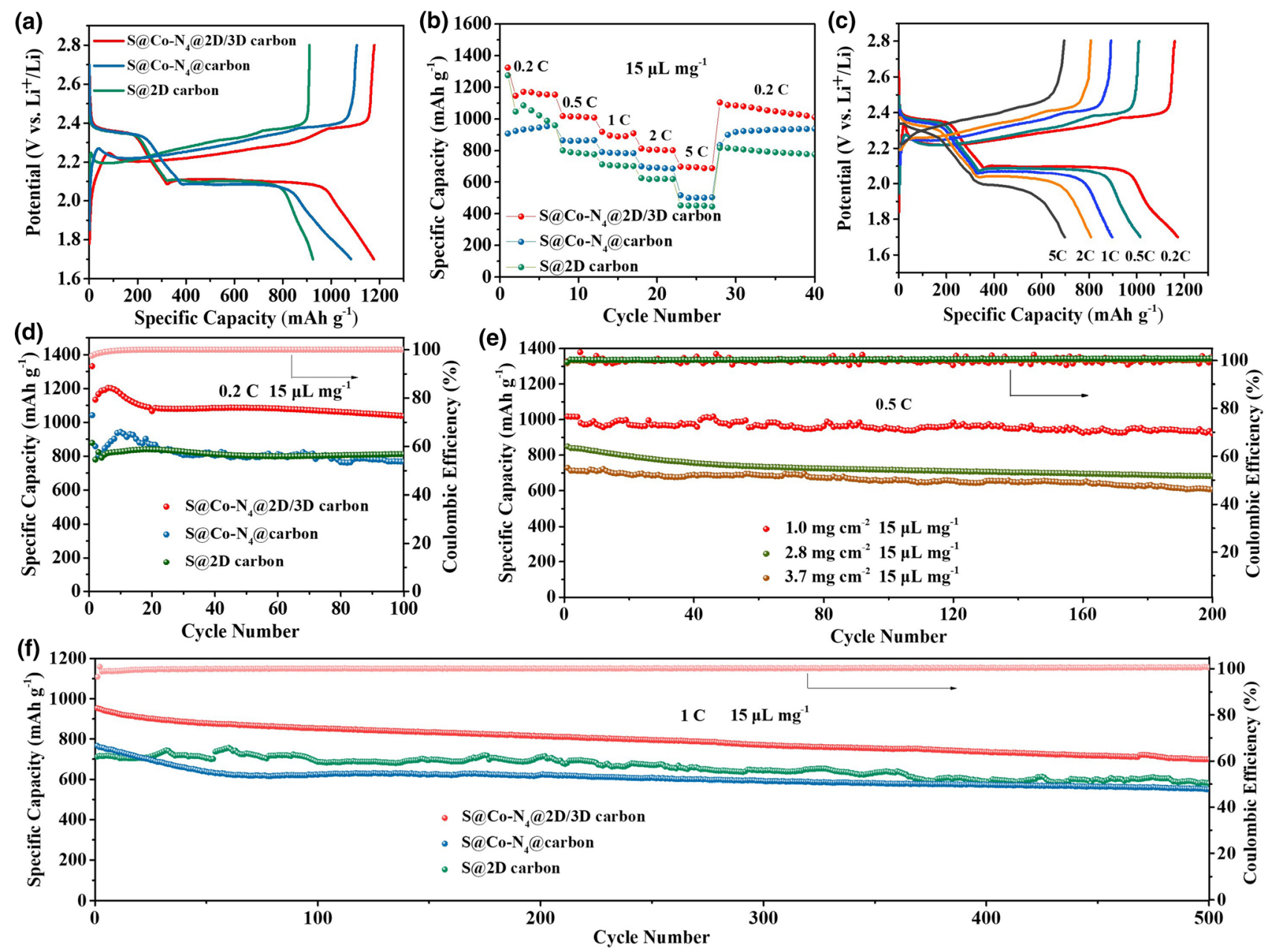

Fig. 6 a Charge-discharge profiles at $0.2 \mathrm{C}$ and b rate performance at various current rate of S@Co-N $\mathrm{N}_{4} @ 2 \mathrm{D} / 3 \mathrm{D}$ carbon, S@Co-N $\mathrm{N}_{4} @ \mathrm{carbon}$ and S@2D carbon electrodes. c The charge-discharge profiles of the S@Co- $\mathrm{N}_{4} @ 2 \mathrm{D} / 3 \mathrm{D}$ carbon electrode at different current rates. d Cycling stability at $0.2 \mathrm{C}$ and $\mathbf{f}$ cycling stability at $1 \mathrm{C}$ for $\mathrm{S} @ \mathrm{Co}-\mathrm{N}_{4} @ 2 \mathrm{D} / 3 \mathrm{D}$ carbon, S@Co- $\mathrm{N}_{4} @$ carbon and $\mathrm{S} @ 2 \mathrm{D}$ carbon electrodes. $\mathrm{e}$ Cycling performance of $\mathrm{S} @ \mathrm{Co}-\mathrm{N}_{4} @ 2 \mathrm{D} / 3 \mathrm{D}$ carbon with sulfur loading of 1.0, 2.8, and $3.7 \mathrm{mg} \mathrm{cm}^{-2}$ at $0.5 \mathrm{C}$

S@2D carbon [51-54], revealing the favorable enhancement of the charge transfer during the polysulfide conversion reaction because of the synergistic effect of 2D/3D architecture and atomically dispersed $\mathrm{Co}-\mathrm{N}_{4}$.

Figure 6d shows the cycling stability of the S@ Co- $\mathrm{N}_{4} @ 2 \mathrm{D} / 3 \mathrm{D}$ carbon, S@Co- $\mathrm{N}_{4} @$ carbon and S@2D carbon cathode with an $\mathrm{E} / \mathrm{S}$ ratio of $15 \mu \mathrm{L} \mathrm{mg}$. After 100 cycles at a current density of $0.2 \mathrm{C}$, the S@ $\mathrm{Co}-\mathrm{N}_{4} @ 2 \mathrm{D} / 3 \mathrm{D}$ carbon electrode could still maintain a high discharge capacity of $1000 \mathrm{~mA} \mathrm{~h} \mathrm{~g}^{-1}$ with $83.3 \%$ capacity retention and a Coulombic efficiency of nearly $100 \%$, much higher than those of S@Co- $\mathrm{N}_{4} @$ carbon and S@2D carbon. Figure 6e further displays the cycling stability of $\mathrm{S} @ \mathrm{Co}-\mathrm{N}_{4} @ 2 \mathrm{D} / 3 \mathrm{D}$ carbon electrode with different sulfur loading density at a larger density of $0.5 \mathrm{C}$ with an E/S ratio of $15 \mu \mathrm{L} \mathrm{mg}^{-1}$. The $\mathrm{S} @ \mathrm{Co}-\mathrm{N}_{4} @ 2 \mathrm{D} / 3 \mathrm{D}$ carbon electrode can deliver initial capacities of 850 and $728 \mathrm{mAh} \mathrm{g}^{-1}$ and still maintain reversible capacities of 682 and $607 \mathrm{mAh} \mathrm{g}^{-1}$ even after 200 cycles at high sulfur loadings of 2.8 and $3.7 \mathrm{~m} \mathrm{~cm}^{-2}$, respectively. Meanwhile, the $\mathrm{S} @ \mathrm{Co}-\mathrm{N}_{4} @ 2 \mathrm{D} / 3 \mathrm{D}$ carbon cathode with a higher sulfur loading $\left(4.6 \mathrm{mg} \mathrm{cm}^{-2}\right)$ and a lower $\mathrm{E} / \mathrm{S}$ ratio of $8 \mu \mathrm{L}$ $\mathrm{mg}^{-1}$ was also investigated. As shown in Fig. S14, it could maintain the areal capacity as high as $3.6 \mathrm{mAh} \mathrm{cm}^{-2}$ after 100 cycles at $0.2 \mathrm{C}$, further demonstrating the feasibility of $\mathrm{Co}-\mathrm{N}_{4} @ 2 \mathrm{D} / 3 \mathrm{D}$ carbon as a sulfur host for practical 
Li-S batteries. To further illustrate the advantage of S@ Co- $\mathrm{N}_{4} @ 2 \mathrm{D} / 3 \mathrm{D}$ carbon cathode in Li-S battery, the longterm cycle life at a high current density of $1 \mathrm{C}$ with an E/S ratio of $15 \mu \mathrm{L} \mathrm{mg}^{-1}$ was evaluated (Fig. 6f). The S@ Co- $\mathrm{N}_{4} @ 2 \mathrm{D} / 3 \mathrm{D}$ carbon could achieve a remarkable capacity of $700 \mathrm{mAh} \mathrm{g}^{-1}$ over 500 cycles with a low capacity fading of $0.053 \%$ per cycles, which is not only better than $\mathrm{S} @ \mathrm{Co}-\mathrm{N}_{4} @$ carbon and S@2D carbon cathodes but also comparable to the state-of-the-art reported metal-based compounds/C/S cathodes (Table S2).

To further reveal the superiority of $\mathrm{Co}-\mathrm{N}_{4} @ 2 \mathrm{D} / 3 \mathrm{D}$ for suppressing the shuttle effect, lithium foil anodes extracted from cells after 100 cycles at $1 \mathrm{C}$ were investigated. As shown in Fig. S15, the surface of lithium foil in Co- $\mathrm{N}_{4} @ 2 \mathrm{D} / 3 \mathrm{D}$ cells was flat and very smooth, indicating a minimal accumulation of lithium dendrites. However, the surface of Li anode in S@2D carbon- and S@Co- $\mathrm{N}_{4} @$ carbon cells have been severely corroded. The above results further demonstrate that $\mathrm{Co}-\mathrm{N}_{4} @ 2 \mathrm{D} / 3 \mathrm{D}$ has the stronger inhibiting effect for shuttle effect of intermediate lithium polysulfides.

The effect of different $\mathrm{SiO}_{2}$ contents on the morphology, specific surface area and pore volume of porous $3 \mathrm{D}$ carbon materials was also investigated. For convenience, the samples obtained using $0.75,1.5$, and $3.0 \mathrm{~mL}$ tetraethyl orthosilicate were named Co- $\mathrm{N}_{4} @ 2 \mathrm{D} / 3 \mathrm{D}$ carbon- 0.75 , $\mathrm{Co}-\mathrm{N}_{4} @ 2 \mathrm{D} / 3 \mathrm{D}$ carbon, and $\mathrm{Co}-\mathrm{N}_{4} @ 2 \mathrm{D} / 3 \mathrm{D}$ carbon-3, respectively. As shown in Fig. S16a, b, Co-N $\mathrm{N}_{4} @ 2 \mathrm{D} / 3 \mathrm{D}$ carbon-0.75 and Co- $\mathrm{N}_{4} @ 2 \mathrm{D} / 3 \mathrm{D}$ carbon-3 exhibit a similar morphology to $\mathrm{Co}-\mathrm{N}_{4} @ 2 \mathrm{D} / 3 \mathrm{D}$ carbon. The $\mathrm{N}_{2}$ sorption measurement results in Fig. S16c indicate that Co-N $\mathrm{N}_{4} @ 2 \mathrm{D} / 3 \mathrm{D}$ carbon- 0.75 has a Brunauer-Emmett-Teller (BET) surface area of $799 \mathrm{~m}^{2} \mathrm{~g}^{-1}$ and pore volume of 0.718 $\mathrm{cm}^{3} \mathrm{~g}^{-1}$, larger than those of $\mathrm{Co}-\mathrm{N}_{4} @ 2 \mathrm{D} / 3 \mathrm{D}$ carbon (488 $\mathrm{m}^{2} \mathrm{~g}^{-1}$ and $0.649 \mathrm{~cm}^{3} \mathrm{~g}^{-1}$ ) and $\mathrm{Co}-\mathrm{N}_{4} @ 2 \mathrm{D} / 3 \mathrm{D}$ carbon-3 $\left(534 \mathrm{~m}^{2} \mathrm{~g}^{-1}\right.$ and $\left.0.56 \mathrm{~cm}^{3} \mathrm{~g}^{-1}\right)$. The largest surface area and pore volume of $\mathrm{Co}-\mathrm{N}_{4} @ 2 \mathrm{D} / 3 \mathrm{D}$ carbon- 0.75 may be attributed to rich micropores, which is also demonstrated by the pore distribution (Fig. S16d). Moreover, Co- $\mathrm{N}_{4} @ 2 \mathrm{D} / 3 \mathrm{D}$ carbon-0.75, Co- $\mathrm{N}_{4} @ 2 \mathrm{D} / 3 \mathrm{D}$ carbon, and $\mathrm{Co}-\mathrm{N}_{4} @ 2 \mathrm{D} / 3 \mathrm{D}$ carbon-3 were used as sulfur host and accordingly their electrochemical performance was also evaluated. As shown in Fig. S17, Co-N $\mathrm{N}_{4} @ 2 \mathrm{D} / 3 \mathrm{D}$ carbon-0.75- and Co- $\mathrm{N}_{4} @ 2 \mathrm{D} / 3 \mathrm{D}$ carbon-3-based electrodes could maintain capacities of 839 and $756 \mathrm{mAh} \mathrm{g}^{-1}$ over 200 cycles at $0.5 \mathrm{C}$, respectively, lower than that of $\mathrm{Co}-\mathrm{N}_{4} @ 2 \mathrm{D} / 3 \mathrm{D}$ carbon-based electrodes.

\section{Conclusions}

In summary, we have developed a facile strategy for the synthesis of a hierarchically porous three-dimension (3D) carbon architecture assembled by cross-linked carbon leaves with highly dispersed atomic $\mathrm{Co}-\mathrm{N}_{4}$ through a pyrolysis of $\mathrm{SiO}_{2}$-mediated ZIF-L. The porous hierarchical architecture not only effectively buffers the volume change during sulfur lithiation but also provides fast ionic/electronic conductive network for efficient charge transfer. More importantly, the highly accessible $\mathrm{Co}-\mathrm{N}_{4}$ within $2 \mathrm{D} / 3 \mathrm{D}$ carbon functions as an efficient polysulfide regulator to strongly anchor the intermediates against shuttling behavior as well as catalysts to accelerate the sulfur conversion reaction by reducing energy barrier. Benefiting from the structural superiorities, the Li-S cell based on the as-synthesized Co- $\mathrm{N}_{4} @ 2 \mathrm{D} / 3 \mathrm{D}$ carbon exhibited a high sulfur utilization (1171 $\mathrm{mAh} \mathrm{g}^{-1}$ at $0.2 \mathrm{C}$ ), excellent long-term cycling stability (a low capacity fading of $0.053 \%$ per cycles for 500 cycles at $1 \mathrm{C}$ ) and exceptional rate capability (695 $\mathrm{mAh} \mathrm{g}^{-1}$ at $5 \mathrm{C}$ ). Our work may pave a new avenue to develop advanced sulfur host materials for practical $\mathrm{Li}-\mathrm{S}$ batteries.

Acknowledgements This work was financially supported by the National Natural Science Foundation of China (Grant Nos. 51871060, 52071084 and 51831009), Recruit Program of Global Youth Experts and Fudan's Undergraduate Research Opportunities Program (FDUROP). The authors also would like to thank the staff at Beamlines BL14W1 and BL15U1 of the Shanghai Synchrotron Radiation Facility (SSRF, China) for providing the beam time.

Open Access This article is licensed under a Creative Commons Attribution 4.0 International License, which permits use, sharing, adaptation, distribution and reproduction in any medium or format, as long as you give appropriate credit to the original author(s) and the source, provide a link to the Creative Commons licence, and indicate if changes were made. The images or other third party material in this article are included in the article's Creative Commons licence, unless indicated otherwise in a credit line to the material. If material is not included in the article's Creative Commons licence and your intended use is not permitted by statutory regulation or exceeds the permitted use, you will need to obtain permission directly from the copyright holder. To view a copy of this licence, visit http://creativecommons.org/licenses/by/4.0/.

Supplementary Information The online version contains supplementary material available at https://doi.org/10.1007/ s40820-021-00676-6. 


\section{References}

1. Y.F. Liu, H.G. Pan, M.X. Gao, Q.D. Wang, Advanced hydrogen storage alloys for $\mathrm{Ni} / \mathrm{MH}$ rechargeable batteries. J. Mater. Chem. 21, 4743-4755 (2011). https://doi.org/10.1039/C0JM0 $1921 \mathrm{~F}$

2. H.G. Pan, Y.F. Liu, M.X. Gao, Y.F. Zhu, Y.Q. Lei et al., An investigation on the structural and electrochemical properties of $\mathrm{La}_{0.7} \mathrm{Mg}_{0.3}\left(\mathrm{Ni}_{0.85} \mathrm{Co}_{0.15}\right)_{\mathrm{x}}(\mathrm{x}=3.15-3.80)$ hydrogen storage electrode alloys. J. Alloys Compd. 351, 228-234 (2003). https://doi.org/10.1016/S0925-8388(02)01045-9

3. H.G. Pan, Y.F. Liu, M.X. Gao, Y.Q. Lei, Q.D. Wang, A study of the structural and electrochemical properties of $\mathrm{La}_{0.7} \mathrm{Mg}_{0.3}\left(\mathrm{Ni}_{0.85} \mathrm{Co}_{0.15}\right)_{\mathrm{x}}(\mathrm{x}=2.5-5.0)$ hydrogen storage alloys. J. Electrochem. Soc. 150, 565-570 (2005). https://doi.org/10. 1016/j.jallcom.2003.12.011

4. B. Liao, Y.Q. Lei, L.X. Chen, G.L. Lu, H.G. Pan et al., A study on the structure and electrochemical properties of $\mathrm{La}_{2} \mathrm{Mg}\left(\mathrm{Ni}_{0.95} \mathrm{M}_{0.05}\right)_{9}(\mathrm{M}=\mathrm{Co}, \mathrm{Mn}, \mathrm{Fe}, \mathrm{Al}, \mathrm{Cu}, \mathrm{Sn})$ hydrogen storage electrode alloys. J. Alloys Compd. 376, 186-195 (2004). https://doi.org/10.1016/j.jallcom.2003.12.011

5. R.R. Wang, B.S. Li, L.F. Lai, M.Z. Hou, J.C. Gao et al., 3D urchin-like architectures assembled by $\mathrm{MnS}$ nanorods encapsulated in $\mathrm{N}$-doped carbon tubes for superior lithium storage capability. Chem. Eng. J. 355, 752-759 (2019). https://doi.org/ 10.1016/j.cej.2018.08.136

6. Z.L. Chen, R.B. Wu, H. Wang, K.H.L. Zhang, Y. Song et al., Embedding ZnSe nanodots in nitrogen-doped hollow carbon architectures for superior lithium storage. Nano Res. 11, 966978 (2018). https://doi.org/10.1007/s12274-017-1709-x

7. Y. Liu, Z.L. Chen, H.X. Jia, H.B. Xu, M. Liu et al., Irondoping-induced phase transformation in dual-carbon-confined cobalt diselenide enabling superior lithium storage. ACS Nano 13, 6113-6124 (2019). https://doi.org/10.1021/acsnano.9b029 28

8. S.Z. Zhang, N. Zhong, X. Zhou, M.J. Zhang, X.P. Huang et al., Comprehensive design of the high-sulfur-loading Li-S battery based on MXene nanosheets. Nano-Micro Lett. 12, 112 (2020). https://doi.org/10.1007/s40820-020-00449-7

9. Z. Zhang, D. Luo, G.R. Li, R. Gao, M. Li et al., Tantalumbased electrocatalyst for polysulfide catalysis and retention for high-performance lithium-sulfur batteries. Matter 3, 1-15 (2020). https://doi.org/10.1016/j.matt.2020.06.002

10. J.L. Wang, Z. Zhang, X.F. Yan, S.L. Zhang, Z.H. Wu et al., Rational design of porous $\mathrm{N}-\mathrm{Ti}_{3} \mathrm{C}_{2}$ MXene@CNT microspheres for high cycling stability in Li-S battery. Nano-Micro Lett. 12, 4 (2020). https://doi.org/10.1007/s40820-019-0341-6

11. Z.Q. Ye, Y. Jiang, L. Li, F. Wu, R.J. Chen, A high-efficiency CoSe electrocatalyst with hierarchical porous polyhedron nanoarchitecture for accelerating polysulfides conversion in Li-S batteries. Adv. Mater. 32, 2002168 (2020). https://doi. org/10.1002/adma.202002168

12. Y.N. An, C. Luo, D.H. Yao, S.J. Wen, P.T. Zheng et al., Natural cocoons enabling flexible and stable fabric lithium-sulfur full batteries. Nano-Micro Lett. 13, 84 (2021). https://doi.org/ 10.1007/s40820-021-00609-3
13. B. Zhang, C. Luo, Y.Q. Deng, Z.J. Huang, G.M. Zhou et al., Optimized catalytic $\mathrm{WS}_{2}-\mathrm{WO}_{3}$ heterostructure design for accelerated polysulfide conversion in lithium-sulfur batteries. Adv. Energy Mater. 10, 2000091 (2020). https://doi.org/ 10.1002/aenm.202000091

14. E. Cha, M. Patel, S. Bhoyate, V. Prasad, W.B. Choi, Nanoengineering to achieve high efficiency practical lithium-sulfur batteries. Nanoscale Horiz. 5, 808-831 (2020). https://doi.org/ 10.1039/C9NH00730J

15. M. Zhao, B.Q. Li, H.J. Peng, H. Yuan, J.Y. Wei et al., Lithiumsulfur batteries under lean electrolyte conditions: challenges and opportunities. Angew. Chem. Int. Ed. 59, 12636-12652 (2020). https://doi.org/10.1002/anie.201909339

16. S.Y. Zhou, S. Yang, X.W. Ding, Y.C. Lai, H.G. Nie et al., Dual-regulation strategy to improve anchoring and conversion of polysulfides in lithium-sulfur batteries. ACS Nano 14, 7538-7551 (2020). https://doi.org/10.1021/acsnano. $0 \mathrm{c} 03403$

17. C. Ma, Y.M. Feng, X.J. Liu, Y. Yang, L.J. Zhou et al., Dualengineered separator for highly robust, all-climate lithium-sulfur batteries. Energy Storage Mater. 32, 46-54 (2020). https:// doi.org/10.1016/j.ensm.2020.07.034

18. J. Zheng, G.B. Ji, X.L. Fan, J. Chen, Q. Li et al., High-fluorinated electrolytes for Li-S batteries. Adv. Energy Mater. 9, 1803774 (2019). https://doi.org/10.1002/aenm.201803774

19. L.L. Zhang, Y.J. Wang, Z.Q. Niu, J. Chen, Advanced nanostructured carbon-based materials for rechargeable lithiumsulfur batteries. Carbon 141, 400-416 (2019). https://doi.org/ 10.1016/j.carbon.2018.09.067

20. H.B. Xu, Y. Liu, Q.Y. Bai, R.B. Wu, Discarded cigarette filterderived hierarchically porous carbon@graphene composites for lithium-sulfur batteries. J. Mater. Chem. A 7, 3558-3562 (2019). https://doi.org/10.1039/C8TA11615F

21. Z. Li, H.B. Wu, X.W. Lou, Rational designs and engineering of hollow micro-/nanostructures as sulfur hosts for advanced lithium-sulfur batteries. Energy Environ. Sci. 9, 3061-3070 (2016). https://doi.org/10.1016/j.nantod.2017.12.010

22. J.J. Park, S.H. Yu, Y.E. Sung, Design of structural and functional nanomaterials for lithium-sulfur batteries. Nano Today 18, 35-64 (2018). https://doi.org/10.1016/j.nantod.2017.12. 010

23. R.R. Li, X.J. Zhou, H.J. Shen, M.H. Yang, C.L. Li, Conductive holey $\mathrm{MoO}_{2}-\mathrm{Mo}_{3} \mathrm{~N}_{2}$ heterojunctions as job-synergistic cathode host with low surface area for high-loading $\mathrm{Li}-\mathrm{S}$ batteries. ACS Nano 13, 10049-10061 (2019). https://doi.org/10.1021/ acsnano.9b02231

24. Y.G. Zhang, G.R. Li, J.Y. Wang, G.L. Cui, X.L. Wei et al., Hierarchical defective $\mathrm{Fe}_{3-\mathrm{x}} \mathrm{C} @ \mathrm{C}$ hollow microsphere enables fast and long-lasting lithium-sulfur batteries. Adv. Funct. Mater. 30, 2001165 (2020). https://doi.org/10.1002/adfm. 202001165

25. Z.W. Seh, Y.M. Sun, Q.F. Zhang, Y. Cui, Designing highenergy lithium-sulfur batteries. Chem. Soc. Rev. 45, 56055634 (2016). https://doi.org/10.1039/C5CS00410A 
26. X. Liu, J.Q. Huang, Q. Zhang, L.Q. Mai, Nanostructured metal oxides and sulfides for lithium-sulfur batteries. Adv. Mater. 29, 1601759 (2017). https://doi.org/10.1002/adma.201601759

27. J.D. Zhu, P. Zhu, C.Y. Yan, X. Dong, X.W. Zhang, Recent progress in polymer materials for advanced lithium-sulfur batteries. Prog. Polym. Sci. 90, 118-163 (2019). https://doi.org/ 10.1016/j.progpolymsci.2018.12.002

28. G.M. Zhou, S.Y. Zhao, T.S. Wang, S.Z. Yang, H. Chen et al., Theoretical calculation guided design of single-atom catalysts toward fast kinetic and long-life Li-S batteries. Nano Lett. 20, 1252-1261 (2020). https://doi.org/10.1021/acs.nanolett.9b047 19

29. C.G. Wang, H.W. Song, C.C. Yu, Z. Ullah, Z.X. Guan et al., Iron single-atom catalyst anchored on nitrogenrich MOFderived carbon nanocage to accelerate polysulfide redox conversion for lithium sulfur batteries. J. Mater. Chem. A 8, 3421-3430 (2020). https://doi.org/10.1039/C9TA11680J

30. Y.J. Li, J.B. Wu, B. Zhang, W.Y. Wang, G.Q. Zhang et al., Fast conversion and controlled deposition of lithium(poly) sulfides in lithium-sulfur batteries using high-loading cobalt single atoms. Energy Storage Mater. 30, 250-259 (2020). https://doi.org/10.1016/j.ensm.2020.05.022

31. Y.J. Li, G.L. Chen, J.R. Mou, Y.Z. Liu, S.F. Xue et al., Cobalt single atoms supported on $\mathrm{N}$-doped carbon as an active and resilient sulfur host for lithium-sulfur batteries. Energy Storage Mater. 28, 196-204 (2020). https://doi.org/ 10.1016/j.ensm.2020.03.008

32. Z.Z. Du, X.J. Chen, W. Hu, C.H. Chuang, S. Xie et al., Cobalt in nitrogen-doped graphene as single-atom catalyst for high-sulfur content lithium-sulfur batteries. J. Am. Chem. Soc. 141, 3977-3985 (2019). https://doi.org/10.1021/ jacs.8b12973

33. J. Xie, B.Q. Li, H.J. Peng, Y.W. Song, M. Zhao et al., Implanting atomic cobalt within mesoporous carbon toward highly stable lithium-sulfur batteries. Adv. Mater. 31, 1903813 (2019). https://doi.org/10.1002/adma.201903813

34. F. Ma, Y.Y. Wan, X.M. Wang, X.C. Wang, J.H. Liang et al., Bifunctional atomically dispersed $\mathrm{Mo}-\mathrm{N}_{2} / \mathrm{C}$ nanosheets boost lithium sulfide deposition decomposition for stable lithium-sulfur batteries. ACS Nano 14, 10115-10126 (2020). https://doi.org/10.1021/acsnano.0c03325

35. X.P. Han, X.F. Ling, Y. Wang, T.Y. Ma, C. Zhong et al., Generation of nanoparticle, atomic-cluster, and single-atom cobalt catalysts from zeolitic imidazole frameworks by spatial isolation and their use in zinc-air batteries. Angew. Chem. Int. Ed. 58, 5359-5364 (2019). https://doi.org/10. 1002/anie.201901109

36. H.L. Fei, J.C. Dong, C.Z. Wan, Z.P. Zhao, X. Xu et al., Microwave-assisted rapid synthesis of graphene-supported single atomic metals. Adv. Mater. 30, 1802146 (2018). https://doi.org/10.1002/adma.201802146

37. Y.H. He, S. Hwang, D.A. Cullen, M.A. Uddin, L. Langhorst et al., Highly active atomically dispersed $\mathrm{CoN}_{4}$ fuel cell cathode catalysts derived from surfactant-assisted MOFs: carbon-shell confinement strategy. Energy Environ. Sci. 12, 250-260 (2019). https://doi.org/10.1039/C8EE02694G
38. Y. Ha, B. Fei, X.X. Yan, H.B. Xu, Z.L. Chen et al., Atomically dispersed co-pyridinic N-C for superior oxygen reduction reaction. Adv. Energy Mater. 10, 2002592 (2020). https://doi.org/10.1002/aenm.202002592

39. X.X. Wang, D.A. Cullen, Y.T. Pan, S. Hwang, M.Y. Wang et al., Nitrogen-coordinated single cobalt atom catalysts for oxygen reduction in proton exchange membrane fuel cells. Adv. Mater. 30, 1706758 (2018). https://doi.org/10.1002/ adma.201706758

40. F. Wu, C. Pan, C.T. He, Y.H. Han, W.J. Ma et al., A singleatom $\mathrm{Co}-\mathrm{N}_{4}$ electrocatalyst enabling four-electron oxygen reduction with enhanced hydrogen peroxide tolerance for selective sensing. J. Am. Chem. Soc. 142, 16861-16867 (2020). https://doi.org/10.1021/jacs.0c07790

41. H. Yuan, H.J. Peng, B.Q. Li, J. Xie, L. Kong et al., Conductive and catalytic triple-phase interfaces enabling uniform nucleation in high-rate lithium-sulfur batteries. Adv. Energy Mater. 9, 1802768 (2019). https://doi.org/10.1002/aenm. 201802768

42. H.J. Peng, Z.W. Zhang, J.Q. Huang, G. Zhang, J. Xie et al., A cooperative interface for highly efficient lithium-sulfur batteries. Adv. Mater. 28, 9551-9558 (2016). https://doi.org/ 10.1002/adma.201603401

43. Q.P. Wu, X.J. Zhou, J. Xu, F.H. Cao, C.L. Li, Adenine derivative host with interlaced $2 \mathrm{~d}$ structure and dual lithiophilicsulfiphilic sites to enable high-loading Li-S batteries. ACS Nano 13, 9520-9532 (2019). https://doi.org/10.1021/acsna no. $9 \mathrm{~b} 04519$

44. X.C. Gao, D. Zhou, Y. Chen, W.J. Wu, D.W. Su et al., Strong charge polarization effect enabled by surface oxidized titanium nitride for lithium-sulfur batteries. Commun. Chem. 2, 66 (2019). https://doi.org/10.1038/s42004-019-0166-8

45. B. Fei, C.Q. Zhang, D.P. Cai, J.Y. Zheng, Q.D. Chen et al., Hierarchical nanoreactor with multiple adsorption and catalytic sites for robust lithium-sulfur batteries. ACS Nano 15, 6849-6860 (2021). https://doi.org/10.1021/acsnano.0c10603

46. Z.S. Wang, J.D. Shen, J. Liu, X.J. Xu, Z.B. Liu et al., Selfsupported and flexible sulfur cathode enabled via synergistic confinement for high-energy-density lithium-sulfur batteries. Adv. Mater. 31, 1902228 (2019). https://doi.org/10. 1002/adma.201970236

47. L.L. Zhang, D.B. Liu, Z. Muhammad, F. Wan, W. Xie et al., Single nickel atoms on nitrogen-doped graphene enabling enhanced kinetics of lithium-sulfur batteries. Adv. Mater. 31, 1903955 (2019). https://doi.org/10.1002/adma.20190 3955

48. R.C. Wang, C. Luo, T.S. Wang, G.M. Zhou, Y.Q. Deng et al., Bidirectional catalysts for liquid-solid redox conversion in lithium-sulfur batteries. Adv. Mater. 32, 2000315 (2020). https://doi.org/10.1002/adma.202000315

49. R.R. Wang, Z.L. Chen, Y.Q. Sun, C. Chang, C.F. Ding et al., Three-dimensional graphene network-supported Co, $\mathrm{N}$-codoped porous carbon nanocages as free-standing polysulfides mediator for lithium-sulfur batteries. Chem. Eng. J. 399, 125686 (2020). https://doi.org/10.1016/j.cej.2020. 125686 
50. D. Luo, Z. Zhang, G.R. Li, S.B. Cheng, S. Li et al., Revealing the rapid electrocatalytic behavior of ultrafine amorphous defective $\mathrm{Nb}_{2} \mathrm{O}_{5-\mathrm{x}}$ nanocluster toward superior $\mathrm{Li}-\mathrm{S}$ performance. ACS Nano 14, 4849-4860 (2020). https://doi. org/10.1021/acsnano.0c00799

51. Y.F. Yang, W.K. Wang, L.X. Li, B.C. Li, J.P. Zhang, Stable cycling of Li-S batteries by simultaneously suppressing Lidendrite growth and polysulfide shuttling enabled by a bioinspired separator. J. Mater. Chem. A 8, 3692-3700 (2020). https://doi.org/10.1039/C9TA12921A

52. Z.L. Chen, R.B. Wu, M. Liu, H. Wang, H.B. Xu et al., General synthesis of dual carbon-confined metal sulfides quantum dots toward high-performance anodes for sodium-ion batteries. Adv. Funct. Mater. 27, 1702046 (2017). https:// doi.org/10.1002/adfm.201702046

53. Y. Tian, G.R. Li, Y.G. Zhang, D. Luo, X. Wang et al., Lowbandgap Se-deficient antimony selenide as a multifunctional polysulfide barrier toward high-performance lithium-sulfur batteries. Adv. Mater. 32, 1904876 (2020). https://doi.org/ 10.1002/adma.201904876

54. X.F. Yang, X.J. Gao, Q. Sun, S.P. Jand, Y. Yu et al., Promoting the transformation of $\mathrm{Li}_{2} \mathrm{~S}_{2}$ to $\mathrm{Li}_{2} \mathrm{~S}$ : significantly increasing utilization of active materials for high-sulfur-loading Li-S batteries. Adv. Mater. 31, 1901220 (2019). https://doi.org/10. 1002/adma.201901220 